Review Article

\title{
Long Noncoding RNAs and RNA-Binding Proteins in Oxidative Stress, Cellular Senescence, and Age-Related Diseases
}

\author{
Chongtae Kim, ${ }^{1}$ Donghee Kang, ${ }^{2}$ Eun Kyung Lee, ${ }^{1}$ and Jae-Seon Lee ${ }^{2}$ \\ ${ }^{1}$ Department of Biochemistry, The Catholic University of Korea College of Medicine, Seoul 06591, Republic of Korea \\ ${ }^{2}$ Department of Molecular Medicine and Hypoxia-Related Disease Research Center, Inha University College of Medicine, \\ Incheon 22212, Republic of Korea \\ Correspondence should be addressed to Eun Kyung Lee; leeek@catholic.ac.kr and Jae-Seon Lee; jaeslee@inha.ac.kr
}

Received 23 February 2017; Revised 27 April 2017; Accepted 6 June 2017; Published 25 July 2017

Academic Editor: Domenico D'Arca

Copyright ( 2017 Chongtae Kim et al. This is an open access article distributed under the Creative Commons Attribution License, which permits unrestricted use, distribution, and reproduction in any medium, provided the original work is properly cited.

Cellular senescence is a complex biological process that leads to irreversible cell-cycle arrest. Various extrinsic and intrinsic insults are associated with the onset of cellular senescence and frequently accompany genomic or epigenomic alterations. Cellular senescence is believed to contribute to tumor suppression, immune response, and tissue repair as well as aging and age-related diseases. Long noncoding RNAs (lncRNAs) are > 200 nucleotides long, poorly conserved, and transcribed in a manner similar to that of mRNAs. They are tightly regulated during various cellular and physiological processes. Although many lncRNAs and their functional roles are still undescribed, the importance of lncRNAs in a variety of biological processes is widely recognized. RNA-binding proteins (RBPs) have a pivotal role in posttranscriptional regulation as well as in mRNA transport, storage, turnover, and translation. RBPs interact with mRNAs, other RBPs, and noncoding RNAs (ncRNAs) including lncRNAs, and they are involved in the regulation of a broad spectrum of cellular processes. Like other cell fate regulators, lncRNAs and RBPs, separately or cooperatively, are implicated in initiation and maintenance of cellular senescence, aging, and age-related diseases. Here, we review the current understanding of both lncRNAs and RBPs and their association with oxidative stress, senescence, and age-related diseases.

\section{Introduction}

Cellular senescence is a biological process in which cells cease growth permanently. Hayflick and Moorehead firstly described replicative senescence (RS), which is an exhaustion of replicative potential in human diploid fibroblasts after continuous cultivation $[1,2]$. More than a half-century from that first description that early concept of cellular senescence has been remarkably extended in recent days. RS can be considered a defense mechanism that limits proliferation potential of older cells containing irreparable and dangerous mutations. In contrast to RS, which is driven by telomere shortening, cells can prematurely undergo senescence in response to diverse forms of cellular stresses. Stress-induced cellular senescence (SIPS) can be triggered by DNA damage, oncogenic mutations, strong mitotic signals, genomic instability, lack of nutrients, improper cell contacts, and many other factors [3]. An excess of reactive oxygen species
(ROS) specifically participates in induction and maintenance of cellular senescence. ROS including superoxide anion, hydrogen peroxide, and hydroxyl radicals are inevitably generated as byproducts of aerobic metabolism and are also derived from radiation, chemotherapeutic agents, carcinogens, and other intrinsic and extrinsic factors. Physiological ROS level regulates signal transduction, gene expression, and proliferation. However, ROS shifts from physiological to pathophysiological level are referred to as oxidative stress. Oxidative stress results in damage to lipids, proteins, and nuclear and mitochondrial DNA and is involved in various changes, such as epigenetic modification and signaling pathways, finally resulting in cellular senescence [4]. Cellular senescence programs are induced by persistent activation of the p53/p21 stress response pathway and/or the RB/p16 tumor suppressor pathway. Senescent cells are characterized by a variety of phenotypes including enlarged and flattened morphology, senescence-associated $\beta$-galactosidase (SA- $\beta$ - 
Gal) activity, formation of senescence-associated heterochromatin foci (SAHF), and altered gene expression and protein processing [5]. In the last decade, many research groups have demonstrated that anticancer drugs and ionizing radiation can effectively induce SIPS in cancer cells in vitro and in vivo [6]. Currently, in accord with the role of senescence-associated secretory phenotypes (SASP) in tumor prevention, therapy-induced senescence is considered a powerful strategy for cancer treatment [7]. Although senescent cells irreversibly lose their dividing capability, they are metabolically active and secrete a myriad of SASP-related factors including cytokines, chemokines, growth factors, and proteases [1]. SASP can influence multiple facets of tissue microenvironments and contribute to the inflammatory response and many other aging phenotypes. Since cellular senescence can potentially contribute to various physiological and pathological aging processes, cellular senescence is an important hallmark of human aging and an attractive target for therapeutic exploitation [6-10]. Aging is the gradual deterioration of the physical, mental, and biological state of an organism with time, eventually resulting in increased vulnerability to death. Moreover, aging is the irreversible loss of physiological integrity and the major risk factor in various age-related diseases such as neurodegenerative diseases, immune response, metabolic diseases, muscle dysfunction, atherosclerosis, and cataract. Various factors and processes have been implicated in the initiation, regulation, and progression of the aging process. An "oxidative stress theory of aging" was proposed long ago, and oxidative stress is primarily associated with cellular senescence and aging. Several studies have shown that transcriptional events are implicated in the regulation of gene expression during oxidative stress responses, cellular senescence, and the pathogenesis of age-related diseases [11-14]. Activation of transcriptional factors such as p53, NF- $\kappa \mathrm{B}$, HIF-1 $\alpha$, CEBP, STAT, and E2F1 governs mRNA expression via promoter activation, microRNA induction, and epigenetic regulation in senescence, aging, and age-related disease [11]. Schematic relationships among DNA damage and oxidative stress, cellular senescence, and age-related diseases are shown in Figure 1. Herein, we revisit current knowledge of the mechanistic, functional, and pathological roles of long noncoding RNAs (lncRNAs) and RNA-binding proteins (RBPs) that are primarily related to DNA damage, oxidative stress, cellular senescence, aging, and age-related diseases. In this review, we will not describe lncRNAs and RBPs associated with telomeres and cancer because those topics have already been extensively introduced in other reviews [15-18].

\section{Long Noncoding RNAs}

The lncRNAs are transcripts more than 200 nucleotide long that have no protein-coding potential. Moreover, they are poorly conserved, transcribed from the intergenic and intronic regions of genome primarily by polymerase II, $5^{\prime}$ methylcapped, and polyadenylated in manner similar to that of mRNAs [16]. The lncRNAs modulate gene expression at all regulation levels: transcriptional, posttranscriptional, translational, and posttranslation. They can regulate gene expression via interaction with chromatin modifiers, RBPs, DNA, and RNA [15]. To date, many lncRNAs have been characterized. Most of those are nuclear localized and act as enhancer RNAs (eRNAs), chromatin modifiers via recruitment of various DNA methyltransferases, and histone modifiers via Polycomb repressive complexes or histone methyltransferases [16]. Some lncRNAs are transported to the cytoplasm and regulate translation or mRNA stability. Moreover, lncRNAs affect key cellular processes such as proliferation, differentiation, quiescence, senescence, stress and immune response, and many other cellular functions related to the biology of aging [19].

\subsection{DNA Damage Response and Oxidative Stress}

2.1.1. LincRNA-p21. LincRNA-p21 is $3.1 \mathrm{~kb}$ long and is transcribed from the opposite strand to p21 (CDKN1A) in a p53dependent manner [20]. LincRNA-p21, which is also induced by hypoxia and/or hypoxia inducible factor- $1 \alpha$ (HIF- $1 \alpha)$, is able to bind HIF- $1 \alpha$ and VHL, and it disrupts the VHLHIF- $1 \alpha$ interaction. This disassociation attenuates VHLmediated HIF- $1 \alpha$ ubiquitination and causes HIF- $1 \alpha$ accumulation. These results indicate a positive feedback loop between HIF- $1 \alpha$ and lincRNA-p21 under hypoxia [21]. In addition, LincRNA-p21 is highly inducible by UVB through a p53-dependent pathway and plays key role in the UVBinduced apoptotic pathway [22].

2.1.2. LincRNA-RoR. LincRNA-RoR, a $2.6 \mathrm{~kb}$ long transcript, was first described as having potentially important functions in embryonic stem cells and induced pluripotent stem cells (iPSCs) [19]. LincRNA-RoR regulates genes involved in the p53 response, such as responses to oxidative stress and DNA damage [23]. Depletion of p53 can partially rescue the apoptotic phenotype by ablation of lincRNA-RoR. LincRNA-RoR dramatically represses DNA damage-induced p53 compared to that in unstressed cells. Depletion of lincRNA-RoR did not regulate p53 mRNA levels, suggesting posttranscriptional regulation of p53. Mechanistically, lincRNA-RoR has a 28-base heterogeneous nuclear ribonucleoprotein I- (hnRNP I-) binding motif and directly interacts with phosphorylated hnRNP I in the cytoplasm. The interaction between lincRNA-RoR and phosphorylated hnRNP I directly represses p53 translation and results in the modulation of cell-cycle progression and apoptosis. Thus, lincRNA-RoR and p53 act within an autoregulatory feedback loop in response to cellular stress [24]. A recent study revealed that $\operatorname{lin} C R N A-R o R$ can epigenetically regulate the expression of TESC by recruiting G9A methyltransferase in the TESC promoter [25].

2.1.3. Pint. Pint (p53-induced noncoding transcript), previously named lincRNA-Mkln1, has highly conserved canonical p53-binding motifs in the promoter and is a transcriptional target of p53 [20]. Pint is a nuclear lincRNA and is transcribed from an intergenic region on mouse chromosome 6. Pint has three p53 response elements and is directly regulated by p53 upon DNA damage [26]. Depletion of Pint significantly decreases cell proliferation, and overexpression of Pint conversely increases cell growth. Pint directly interacts with Polycomb repressive complex 2 


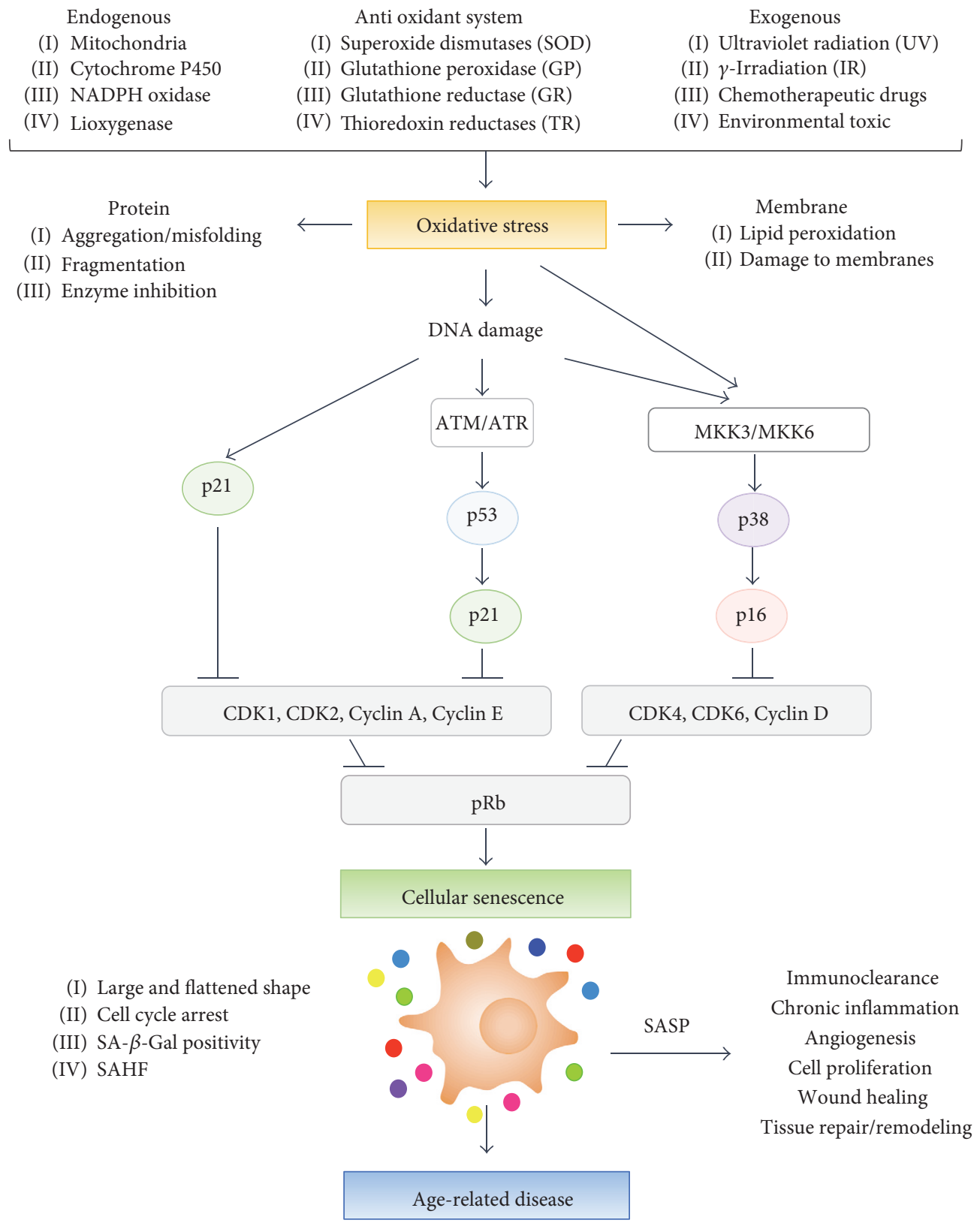
(I) Neurodegenerative diseases
(V) Atherosclerosis
(II) Immune response
(VI) Cataract
(III) Diabetes
(VII) Metabolic diseases
(IV) Muscle dysfunction

Figure 1: Schematic relationships among DNA damage and oxidative stress, cellular senescence, and age-related diseases.

(PRC2) and represses expression of PRC2 targeting genes via H3K27 trimethylation. PINT, the pint human ortholog, is also regulated by $\mathrm{p} 53$. However, overexpressed PINT diminishes tumor cell proliferation, indicating both analogy and difference between murine Pint and human ortholog PINT [26].

2.1.4. PANDA. To detect functional noncoding RNAs (ncRNAs) in the regulatory region of human cell-cycle genes, ultrahigh-density array fabrication was performed and the lncRNA PANDA (P21-associated ncRNA DNA damage-activated) was identified at the CDKN1A locus [27]. PANDA is specifically induced by DNA damage in a p53-dependent manner. PANDA is a $5^{\prime}$-capped, polyadenylated lncRNA located approximately $4.5 \mathrm{~kb}$ upstream of the CDKN1A transcriptional start site. In human fibroblasts treated with doxorubicin, PANDA prevents NF-YA activation, through its association with NF-YA, finally suppressing transcription of proapoptotic genes. Thus, PANDA induced by DNA damage impedes apoptosis through recruitment 
of NF-YA [27]. Another study reported that PANDA can stabilize p53 proteins in response to DNA damage [28]. In addition, it was revealed that silencing of PANDA causes G1 arrest via an increase in the mRNA level of cyclindependent kinase inhibitor p18 [29].

2.1.5. LncRNA-JADE. LncRNA-JADE is induced by ATM$\mathrm{NF}-\kappa \mathrm{B}$ signaling and is mainly localized in the nucleus in the DNA damage response (DDR) [30]. In response to DDR, increased $\ln c R N A-J A D E$ interacts with breast cancer type 1 susceptibility protein (Brca1) and induces expression of Jade1, a major component of human acetylase binding to ORC 1 (HBO1) histone acetylation complex. Consequently, depletion of $\ln c R N A-J A D E$ renders sensitivity to DNA damaging drugs through the functional link between DDR and histone $\mathrm{H} 4$ acetylation in the DDR. [30].

2.1.6. H19. H19 was first described as an imprinted ncRNA transcript at the Igf2 locus. A number of studies have reported that $H 19$ is upregulated in both primary and metastatic tumors and is closely involved in migration, angiogenesis, and inflammatory diseases [31]. HIF- $1 \alpha$ and p53 are involved in the upregulation of H19 in hypoxic cancer cells [32]. Recently, it was demonstrated that $H 19$ expression is elevated under hypoxic conditions in mesenchymal stem cells [33]. In addition, overexpression of $H 19$ in diabetic rats can attenuate oxidative stress, inflammation, and apoptosis [34].

2.1.7. ANRIL. ANRIL (antisense noncoding RNA in the INK locus) is transcribed in the antisense direction to the INK4BARF-INK4A locus and is transcriptionally upregulated by the transcription factor E2F1 in an ATM-dependent manner after DNA damage. Such elevated levels of ANRIL suppress the expression of INK4A-ARF-INK4B in the late-DDR stage, allowing negative feedback to the DDR. Thus, ANRIL helps the cell to return to a normal status at the completion of DNA repair [35].

2.1.8. LncRNA-LET. LncRNA-LET (lncRNA low expression in tumor) transcripts are underexpressed in tumor tissues compared to their expression in paired nontumor tissues [36]. Moreover, $L n c R N A-L E T$ is downregulated by hypoxiainduced histone deacetylase 3 (HDAC3) under hypoxic conditions. $L n c R N A-L E T$ is associated with degradation of nuclear factor of activated T cells $90 \mathrm{kDa}$ (NF90) protein via the regulation of ubiquitin-proteasome pathway. Since NF90 stabilizes HIF- $1 \alpha$ mRNA without altering HIF- $1 \alpha$ transcriptional activity, $\ln R R N A-L E T$ finally decreases HIF- $1 \alpha$ stability due to its association with NF90. These findings illustrate that $\ln C R N A-L E T$ could be a key regulator of hypoxia signaling [36].

2.1.9. LINK-A. LINK-A (long intergenic noncoding RNA for kinase activation) is $1.5 \mathrm{~kb}$ long and mainly localized in the cytoplasm [37]. LINK-A facilitates breast tumor kinase (BRK) activation through the recruitment of BRK to the EGFR: GPNMB heterodimeric complex upon HB-EGF stimulation. Consequently, activated BRK induces phosphorylation of HIF-1 $\alpha$ at Tyr565 and inhibits hydroxylation of HIF- $1 \alpha$, finally resulting in HIF- $1 \alpha$ stabilization. In addition,
LINK-A interacts with leucine-rich repeat kinase 2 (LRRK2) and enhances phosphorylation of HIF- $1 \alpha$ at Ser797. Phosphorylation of Ser797 increases transcriptional activation of HIF- $1 \alpha$ via HIF- $1 \alpha-$ p300 interaction. These events illustrate the magnitude and diversity of cytoplasmic lncRNA LINK-A in signal transduction related to HIF- $1 \alpha$ under normoxic conditions [37].

\subsection{Cellular Senescence and Aging}

2.2.1. 7SL. 7SL is a $300 \mathrm{bp}$ long transcript and an RNA component of signal recognition proteins (SRP) [38]. 7SL is widely upregulated in cancer tissues and involved in cell proliferation. $7 S L$ decreases p 53 translation and accumulation by interacting with the 3 - -untranslated region (3'-UTR) of TP53 mRNA, which encodes tumor suppressor p53. Depletion of $7 S L$ increases the occupancy of HuR to TP53 mRNA and p53 production. $7 S L$-depleted cells undergo cellular senescence and autophagy, indicating that $7 S L$ promotes cell growth via $\mathrm{p} 53$ suppression [39].

2.2.2. HOTAIR. HOTAIR (HOX antisense intergenic RNA) was first identified as HOX IncRNA located in the HOXC locus through transcriptomic analyses of HOX loci [40]. This antisense lncRNA increases the occupancy of Suz12 on the HOXD locus and silences HOXD locus genes by changing the chromatin structure [40]. HOTAIR enhances cancer progression and malignancy by leading to altered H3K27 methylation due to retargeting of PRC2 [41]. Depletion of HOTAIR induces cell-cycle arrest in various cancer types. In addition, HOTAIR can contribute to cellular senescence via a positive feedback loop cascade of an NF- $\kappa$ B-HOTAIR axis [42].

2.2.3. UCA1. UCA1 (urothelial carcinoma-associated 1), an lncRNA with a length of $1.4 \mathrm{~kb}$, was first identified in bladder cell carcinoma [43]. UCA1, a direct target of coactivator of $\mathrm{AP} 1$ and estrogen receptor $\alpha(\mathrm{CAPER} \alpha) / \mathrm{T}-\mathrm{box} 3$ (TBX3) repression, sequesters hnRNP I, which suppresses transcription of CDKN2A and destabilizes CDKN2A mRNA [44]. Oncogenic stress dissociates the CAPER $\alpha /$ TBX3 corepressor and activates UCA1. CAPER $\alpha /$ TBX 3 and UCA 1 coordinately induce oncogene-induced senescence (OIS). In addition, UCA1 can bind with hnRNP I and competitively inhibit hnRNP I binding to $p 27$ mRNA [45]. hnRNP I enhances translation of $p 27 \mathrm{mRNA}$, and there is a negative correlation between p27 expression and UCA1 level.

2.2.4. LincRNA-p21. Overexpressed lincRNA-p21 increases p21 expression at both mRNA and protein levels, and it impedes cell-cycle progression [46]. LincRNA-p21 is necessary for the recruitment of hnRNP $\mathrm{K}$ to the p53 response element and for increasing the binding efficiency of p53 on the p21 promoter region. Moreover, lincRNA-p21 affects the G1/S checkpoint and p21 levels through deregulated expression and altered chromatin state of some Polycomb target genes. Thus, lincRNA-p21 is required for the positive regulation of p21 expression and finally is involved in cellular senescence [46]. 
2.2.5. ANRIL. ANRIL is a $3.8 \mathrm{~kb}$ long lncRNA transcribed in an antisense orientation from the INK4B/ARF/INK4A gene cluster, and it overlaps with the promoter of p14/ARF and the two exons of p15/CDKN2B [47]. ANRIL is required for the recruitment of chromobox (CBX7), a component of $\mathrm{PRC} 1$, to the INK4B/ARF/p16 gene locus. This complex exhibits high-affinity binding to methylated histone $\mathrm{H} 3$ at lysine 27 (H3K27me) and represses the transcription of INK4b/ARF/INK4a [48]. Moreover, depletion of ANRIL disrupts the binding of suppressor of zeste 12 protein homolog (Suz12), a component of PRC2, to INK4B locus, and increases the expression of p15 $[49,50]$. Recent studies have reported that ANRIL promotes silencing of KLF2 and P21 transcription via epigenetic silencing [51]. Such epigenetic transcriptional repression of INK4B/ARF/INK4A by ANRIL, which is associated with senescence, was reviewed by Aguilo et al. [52].

2.2.6. ANRASSF1. ANRASSF1 (antisense intronic noncoding RASSF1) is an intronic lncRNA transcribed from the antisense to RAS-association domain family member $1 \mathrm{~A}$ (RASSF1A) gene [53]. RASSF1A, a tumor suppressor gene, is associated with cell-cycle arrest and senescence via p53independent regulation of p21 [54]. Highly expressed ANRASSF1 recruits PRC2 to the RASSF1A promoter and increases the $\mathrm{H} 3 \mathrm{~K} 27 \mathrm{me} 3$ level, resulting in decreased RASSF1A expression. Therefore, ANRASSF1 mediates cellular senescence through the epigenetic inactivation of the RASSF1A gene [53].

2.2.7. PANDA. PANDA (P21 associated ncRNA DNA damage-activated) is capable of interacting with scaffoldattachment-factor A (SAFA) [55]. SAFA is a nuclear protein that is able to bind DNA and RNA, including ncRNA, and is involved in transcriptional and posttranscriptional regulation by acting as an adaptor molecule for DNA-RNAprotein interactions [56]. In proliferating cells, the SAFA and $P A N D A$ interaction recruits Polycomb repressive complex 1 (PRC1) and PRC2 complexes to senescence target genes including CDKN1A in order to silence their expression [55]. Thus, PANDA depletion leads to senescence phenotypes by derepression of p21 due to disruption of SAFAPANDA-PRC interactions. However, in senescent cells, PANDA sequesters transcription factor NF-YA and limits the expression of NF-YA-E2F-coregulated proliferationpromoting genes. Therefore, $P A N D A$ levels modulate cell fates to enter or exit from senescence [55].

2.2.8. FAL1. FAL1 (focally amplified lncRNA on chromosome 1) was identified from a genome-wide analysis of somatic copy number alterations [57]. FAL1 interacts with epigenetic repressor BMI1 protein, a subcomponent of PRC1, and increases BMI1 stability. Thus, FAL1 can negatively regulate a large number of genes such as CDKN1A, $F A S$, and BTG2. In addition, FAL1 promotes tumor proliferation and represses senescence primarily by decreasing CDKN1A transcription [58].

2.2.9. MIR31HG. Whereas MIR31HG $\operatorname{lncRNA}$ is upregulated during OIS, its depletion promotes p16-dependent senescence phenotypes [59]. MIR31HG interacts with the INK4A and MIR31HG genomic loci and mediates repression of the INK4A locus with Polycomb group (PcG) proteins. MIR31HG plays a role during OIS as a transcriptional regulator of $\mathrm{p} 16$ via direct interaction with PcG proteins [59].

2.2.10. SALNR. SALNR (senescence-associated long noncoding RNA) expression is downregulated in senescent human fibroblasts. SALNR interacts with NF90, a RNA-binding protein involved in microRNA (miRNA) biogenesis, and regulates its nuclear localization. SALNR and the NF90 complexes impede premature senescence through the regulation of senescence-associated miRNAs, specifically miR-181a and $\operatorname{miR}-22[60]$.

2.2.11. VAD. $V A D$ is a vlincRNA (very long intergenic ncRNA) that is differentially expressed in RAF-induced senescence and is localized in the chromatin. $V A D$ is involved in the maintenance of senescence features. Mechanistically, VAD modulates chromatin structure in cis and increases the expression of INK4 genes in trans. VAD decreases the occupancy of the repressive histone variant $\mathrm{H} 2 \mathrm{~A} . \mathrm{Z}$ at INK4 promoters during senescence induction [61].

\subsection{Age-Related Diseases}

\subsubsection{Neurodegenerative Diseases}

(1) Alzheimer's Disease. Alzheimer's disease (AD) is the most common neurodegenerative disease and accounts for the majority of dementia cases. Amyloid $\beta(\mathrm{A} \beta)$ plaques and neurofibrillary tangles are the two primary pathological hallmarks of AD. The amyloid cascade hypothesis suggests that deposition of $\mathrm{A} \beta$ might be cause of neuronal dysfunction and death of brain tissue in AD. Recently, the cleavage patterns of amyloid precursor protein (APP) to A $\beta$ peptides $\left(\mathrm{A} \beta_{1-40}\right.$ and $\left.\mathrm{A} \beta_{1-42}\right)$ by secretases, small oligomers of $\mathrm{A} \beta$ (2 12 peptides), $\mathrm{A} \beta$ concentration, and $\mathrm{A} \beta$ stability have been proposed as important factors in $\mathrm{AD}$ [62].

$B C 200$ is a $200 \mathrm{bp}$ long RNA pol III-transcribed IncRNA that is predominantly expressed in the brain [63]. BC200 is downregulated in normal aged brains, but $B C 200$ is significantly upregulated in AD brains. Specifically, BC200 is highly expressed in AD-related regions (e.g., Broadmann's area 9) compared to its expression in nonrelated regions (e.g., area 17) [64].

$B A C E 1-A S$ (BACE1-antisense transcript) is a $2 \mathrm{~kb}$ long transcript from the antisense strand of $\beta$-secretase- 1 (BACE1) and is a crucial enzyme in AD pathology. BACE1$A S$ regulates $B A C E 1 \mathrm{mRNA}$ and protein expression in vitro and in vivo. In response to cell stress, elevated $B A C E 1$ $A S$ increases BACE1 mRNA and protein levels due to RNA duplex formation, generating additional A $\beta$ 1-42 peptides [65]. Moreover, modulation of BACE1 and the $B A C E 1-A S$ transcript can participate in the alteration of oligomeric $\mathrm{A} \beta$ aggregation pattern and $\mathrm{A} \beta$-related hippocampal neurogenesis [66].

NDM29 (neuroblastoma differentiation marker 29) is a cytoplasmic lncRNA transcribed by polymerase (pol) III. NDM29 is highly expressed in neuroblastoma cells and is involved in neuroblastoma maturation [67]. In addition, 
elevated NDM29 expression is detected in the brain of AD patients. NDM29-dependent cell maturation induces APP synthesis and results in an increase of $\mathrm{A} \beta$ secretion. Moreover, an increase in the production of copies of NDM29 transcripts can be driven by inflammatory stimuli [68].

$17 \mathrm{~A}$ is a $159 \mathrm{bp}$ long lncRNA synthesized by RNA pol III that induces an increase of GABA B2 receptor splice variant $B$, which affects GABA-B function. Thus, $17 A$ impairs GABA-B signaling and might enhance $A \beta$ secretion. In addition, $17 A$ is upregulated in $\mathrm{AD}$ compared to its level in control tissues [69]. Other lncRNAs such as 51A, NAT-Rad18, and GNDFOS might also be involved in $\mathrm{AD}[70,71]$.

(2) Parkinson's Disease. Parkinson's disease (PD) is a common and complex neurodegenerative disease characterized by defects in the body's motor functions (slow or lack of movements, and tremor). The classical features of PD are associated with Lewy bodies and loss of dopaminergic neurons in the substantia nigra pars compacta in the midbrain. The resultant deficiency of dopamine ultimately induces movement disorder, which is a characteristic of PD [72].

AS Uchl1 (antisense to mouse ubiquitin carboxy-terminal hydrolase L1) is a $1.2 \mathrm{~kb}$ lncRNA transcribed from the opposite strand of the ubiquitin carboxy-terminal hydrolase L1 (Uchl1) gene and induces UChl1 translation. AS Uchl1 is expressed in mesencephalic regions, which are degenerated in PD. AS Uchl1 is regulated by Nur11, a major transcription factor functioning in the differentiation and maintenance of dopaminergic neurons. Expressions of AS Uchl1 and UCHL1 have been decreased in PD models in vitro and in vivo [73].

NaPINK1 is transcribed from the antisense direction of the PINK1 gene, which is implicated in PD through an association with unbalanced mitochondrial homeostasis. As naPINK1 is able to stabilize PINK1 splice variant (svPINK1) expression in neurons via a dsRNA-mediated mechanism, naPINK1 might be involved in $\mathrm{PD}$ through regulation of the PINK1 locus $[71,74]$.

(3) Huntington's Disease. Huntington's disease (HD) is a dominantly inherited disease characterized by chorea, psychiatric problems, and dementia. HD is caused by mutation in the huntingtin (HTT) gene. Expansion of the CAGtriplet repeat sequence within the first exon of HTT results in abnormal protein production, which gradually leads to death of brain cells [75].

TUG1 (taurine upregulated gene 1) was first identified in a screen for genes upregulated by taurine in developing retinal cells [76] and, subsequently, in a genome analysis to examine lncRNAs physically associated with chromatinmodifying complexes [77]. Depletion of TUG1 increases the phenotypes of apoptosis [76], and TUG1 expression is elevated in HD [78]. Mechanistically, TUG1, a direct transcriptional target of p53, combines with enhancer of zeste homolog 2 (EZH2), a component of the PRC2 complex, and epigenetically regulates gene expression. TUG1 and EZH2 bind to the promoter of homeobox B2 (HOXB7) and represses HOXB7 expression [79].
MEG3 is highly expressed in adult human and mouse brains and is differentially expressed in HD patients. MEG3 can associate with the PRC2 complex and is found in the chromatin region in the nucleus, suggesting that $M E G 3$ might be involved in epigenetic regulation in $\mathrm{HD}[16,78]$. Other lncRNAs such as HAR1 (human accelerated region 1), NEAT1 (nuclear paraspeckle assembly transcript 1), and DGCR5 (DiGeorge syndrome critical region gene 5) also exhibit altered expression in HD patients, as shown by microarray studies [16, 78].

HTTAS (huntingtin antisense) is a natural antisense transcript at the HD CAG repeat. HTTAS is mainly spliced into HTTAS-V1 (exons 1 and 3) and HTTAS-V2 (exons 2 and 3). HTTAS-V1 expression is reduced in human HD frontal cortex, and its overexpression negatively regulates HTT transcription [80].

2.3.2. Immune Response. The immune response is a wide variety of physiological and pathological processes originating from immune system activation. It is triggered by pathogens, antigens, tissues injury, and other noxious stimulations. The innate immune response provides immediate defense against infection and is evolutionarily conserved. The adaptive immune response is highly specific to particular pathogens and provides long-lasting protection. Adaptive immune responses are mainly mediated antibody and cellmediated immune responses. The inflammatory response is considered an innate immune response. Inflammation functions to eliminate the initial cause of the original insult and to initiate tissue repair, which are regulated by immune mediators including cytokines, chemokines, and soluble inflammatory proteins [81].

THRIL (TNF $\alpha$ - and hnRNP L-related immunoregulatory lincRNA) is an approximately $2 \mathrm{~kb} \operatorname{lncRNA}$ that changes expression upon activation of innate immune signaling in macrophages. THRIL recruits heterogeneous nuclear ribonucleoprotein L (hnRNP L) to the TNF $\alpha$ promoter and increases the secretion of $\mathrm{TNF} \alpha$, an inflammatory cytokine. An increase in TNF $\alpha$ downregulates THRIL expression via a negative feedback mechanism. Moreover, THRIL is associated with maintaining expression of many innate immunityassociated genes [82].

Lnc-DC is exclusively expressed in human conventional dendritic cells and is involved in dendritic cell (DC) differentiation and DC capacity to stimulate T cell activation. LnC$D C$ prevents signal transducer and activator of transcription 3 (STAT3) dephosphorylation by SHP1 through a direct association with STAT3. Lnc-DC is known as a specific regulator of DC differentiation and function [83].

Lnc-IL7R, which overlaps with the 3'-UTR of interleukin-7 receptor $\alpha(I L 7 R)$ gene, shows altered expression in response to LPS stimulation. $L n c-I L 7 R$ functionally diminishes the LPSinduced inflammatory response and is mechanistically involved in trimethylation of $\mathrm{H} 3 \mathrm{~K} 27$ at the E-selectin and VCAM-1 promoters. $L n c-I L 7 R$ is a regulator of proinflammatory genes via epigenetic modification [84].

LincRNA-EPS is downregulated in response to inflammatory triggers. Gain-of-function and rescue studies have revealed that lincRNA-EPS represses transcriptions of 
immune response genes by interacting with hnRNP L. LincRNA-EPS has a critical role in restraining lethal inflammatory responses [85].

2.3.3. Diabetes. Diabetes is a metabolic disease associated with high blood sugar levels. Diabetes can be caused by the pancreas not producing insulin (type 1 diabetes (T1DM)) or by insulin resistance (type 2 diabetes (T2DM)). The majority of type 1 diabetes cases are attributed to a $\mathrm{T}$ cellmediated autoimmune attack, which leads to loss of the insulin-producing beta cells of the islets of Langerhans in the pancreas. It is traditionally termed juvenile diabetes and is partially inherited. T2DM is the most common type of diabetes. Insulin resistance in T2DM might be combined with reduced insulin secretion and defective responsiveness of insulin receptors [86].

$R N C R 3$ is involved in diabetes-induced retinal neurodegeneration [87]. Knockdown of RNRC3 reduces the release of cytokines and results in fewer apoptotic retinal cells and improved visual function. RNCR3 increases in response to high glucose stress in vitro and in vivo and regulates retinal endothelial cell function through the RNCR3/KLF2/miR185-5p network [88].

MEG3 is reduced in the retinas of STZ-induced diabetic mice and in endothelial cells under high glucose and oxidative stress. MEG3 knockdown aggravates diabetes-related retinal vessel dysfunction, which is mainly mediated by activation of PI3K/AKT signaling [89]. MEG3 expression is upregulated in hepatocytes through histone acetylation in high-fat diet and ob/ob mice. In addition, MEG3 is involved in hepatic insulin resistance via an increase in FoxO1 expression [90].

HI-LNC25 was first identified in a transcriptome mapping study of human pancreatic islets and $\beta$ cells [87]. HI-LNC25 is a $\beta$ cell-specific lncRNA and an integral component of $\beta$ cell differentiation and maturation [87]. Depletion of HI-LNC25 decreases expression of GLIS3 mRNA, which is associated with pancreatic $\beta$ cell function and mass maintenance [91]. KCNQ1OT1 and HI-LNC45, which were previously genetically associated with T2DM [92], are significantly dysregulated in diabetes islets [91].

2.3.4. Muscle Dysfunction. Muscle development is a multistep process that includes myogenesis, muscle differentiation, and regeneration. Myogenesis is a tightly regulated developmental program to direct myoblasts to form muscle fibers. Myogenic pathways are primarily governed by transcription factors, MyoD, Myf5, myogenin, and MRF4 at the molecular level. Impairment of these processes might be a cause of muscle dysfunction and is an age-related pathological phenomenon [93].

SRA (steroid receptor RNA activator) was initially characterized as an IncRNA functioning to enhance steroid receptor-dependent gene expression [94]. SRA has an unusual property that functions as both $S R A$ RNA and SRAP protein through alternative splicing. The ratio between SRA RNA and SRAP increases during myogenic differentiation, but there is no increase in myotonic dystrophy patients. SRA RNA is an enhancer of myogenic differentiation and myogenic conversion through regulation of MyoD activity [95].

MUNC (MyoD upstream noncoding RNA) is transcribed from the upstream of myogenic differentiation (MyoD), a master transcriptional regulatory factor in muscle differentiation and specifically expressed in skeletal muscle. MUNC depletion reduces myoblast differentiation and impairs muscle regeneration in vivo. $M U N C$ is involved in gene expressions of MyoD, Myogenin, and Myh3 (myosin heavy chain) by acting in trans. MUNC also stimulates the transcription of other genes that are not recognized as MyoD-inducible genes. MUNC is an evolutionarily conserved promyogenic lncRNA that acts directly or indirectly on multiple promoters to increase myogenic gene expression [96].

Linc-RAM (linc RNA activator of myogenesis) is a skeletal muscle-specific lncRNA that localizes in both cytoplasm and nucleus of myoblast. Depletion of linc-RAM impairs myoblast differentiation and muscle regeneration. Mechanistically, linc-RAM promotes assembly of the MyoD-Baf60cBrg1 complex and facilitates the recruitment of the SWI/ SNF core on target myogenic genes, resulting in transcription of myogenic differentiation genes [97].

Other muscle-specific lncRNAs such as linc-MD1 and IncRNA Dum are also involved in the control of muscle gene expression and muscle regeneration $[98,99]$.

2.3.5. Atherosclerosis. Atherosclerosis is the primary cause of heart disease and stroke. It is a chronic disease of the large arteries and is characterized by narrowing or closing of an artery with lipids and fibrous elements. Pathological studies have provided evidence of the critical role of endothelium in mediating inflammation and accumulation of oxidized low-density lipoproteins (LDL) in the intima to recruit monocytes and form macrophage-derived foam cells [100].

SENCR (smooth muscle and endothelial cell-enriched migration/differentiation-associated long noncoding RNA) is an antisense transcript from the first intron of friend leukemia virus integration 1 (FLI1) and is localized in the cytoplasm. SENCR is highly expressed in both smooth muscle and endothelial cells [101]. SENCR impedes migration and proliferation of smooth muscle cells through the regulation of FoxO1 and TRPC6 expression [102]. In addition, SENCR is associated with the regulation of endothelial cell differentiation and angiogenic capacity of human umbilical endothelial cells (HUVECs) [103].

Recent studies have reported several lncRNAs that are involved in atherosclerosis-related smooth muscle cell, endothelial cell, macrophage, and lipid metabolism regulation, suggesting a potential function of such lncRNAs in atherosclerosis development [104].

2.3.6. Cataract. Cataract is characterized by the clouding of an eye's lens. Cataract accounts for half the cases of blindness. Lens proteins denature and degrade over time, and this process is accelerated by age and diseases such as diabetes and hypertension. ROS may be mechanistically involved in cataractogenesis. The only treatment for cataract is surgery in the current state of technology [105]. 


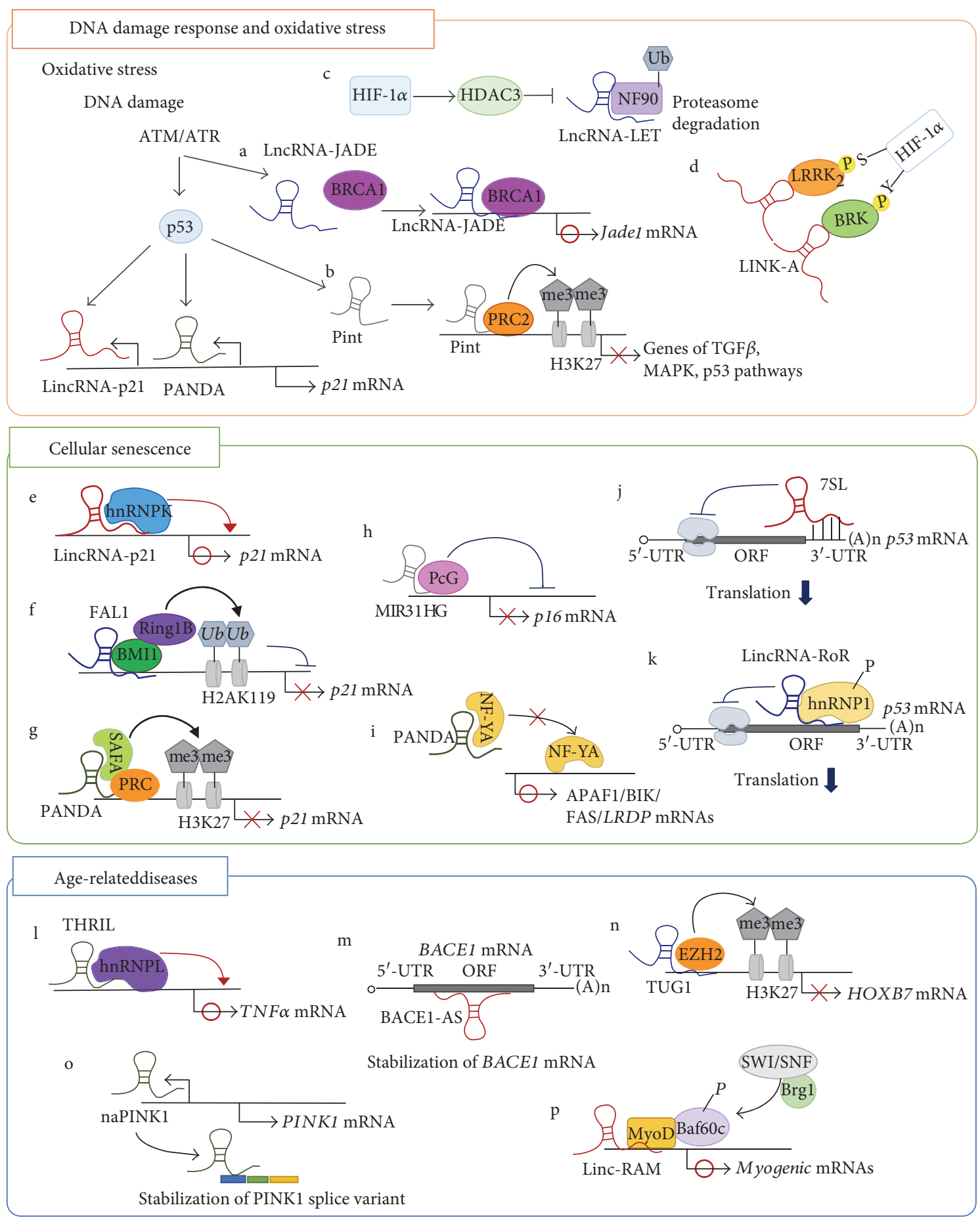

FIGURE 2: A mechanistic diagram of representative IncRNAs involved in DNA damage and oxidative stress, cellular senescence, and related diseases.

LncRNA-MIAT (lncRNA myocardial infarction associated transcript) is highly expressed in patients with cataracts and is involved in the maintenance of human lens epithelial cells (HLECs) whose dysfunction results in cataract formation. MIAT regulates viability, proliferation, and migration of human HLECs in response to oxidative stress. Mechanistically, MIAT acts as a competing endogenous RNA (ceRNA) and can regulate HLEC function through a feedback loop with AKT and miR-150-5p [106].
A mechanistic diagram of representative lncRNAs involved in DNA damage and oxidative stress, cellular senescence, and age-related diseases is shown in Figure 2.

\section{RNA-Binding Proteins}

The RBPs have a pivotal role in mediating posttranscriptional regulation of gene expression by affecting pre-mRNA splicing and maturation as well as mRNA transport, storage, 
turnover, and translation [107]. RBPs can regulate a broad spectrum of cellular process including cell proliferation, death, differentiation, and development, and differential expression or altered activity of certain RBPs is involved in the pathogenesis of several human diseases [107-109]. RBPs interact with mRNAs via a limited set of modular RNA-binding domains (RBDs), such as the heterogeneous nuclear RNA K-homology $(\mathrm{KH})$ domain, RNA recognition motif (RRM), and the zinc-finger (Znf) domain [110]. In addition, RBPs interact with other RBPs and/or ncRNAs such as miRNAs and lncRNAs via cooperative or competitive interaction $[111,112]$.

\subsection{DNA Damage and Oxidative Stress}

3.1.1. $\mathrm{HuR}$. HuR is a member of human antigen ( $\mathrm{Hu})$ family and governs turnover and translation of target mRNAs involved in the regulation of cell proliferation, growth, survival, and differentiation in response to various stresses [113]. HuR has been reported to have protective roles during DDR and oxidative stress by governing RNA stability and translation of various target mRNAs including VEGF, HIF-1 $\alpha, p 53, c-m y c, S I R T 1$, and prothymosin $\alpha$. The roles of $\mathrm{HuR}$ in the regulation of stress response have been extensively reviewed by others $[114,115]$. A recent report has shown that HuR targets and upregulates heme oxygenase 1 (HO1) during oxidative stress [116]. HuR is also implicated in DDR by directly regulating RNA metabolism of p53, WEE1, and non-POU domain-containing octamer-binding protein (NONO, also known as p54NRB) [117, 118]. Esophageal cancer-related gene 2 (ECRG2), a DNA damageinducible tumor suppressor, can regulate XIAP-mediated cell death by downregulating HuR expression [119].

3.1.2. Heterogeneous Nuclear Ribonucleoproteins. Heterogeneous nuclear ribonucleoproteins (hnRNPs) are nuclear proteins regulating a broad spectrum of RNA metabolism including alternative splicing, translocation, and translation [120]. hnRNP A0 is phosphorylated by MAPK-activated protein kinase $2(\mathrm{MK} 2$ ) and stabilizes GADD45 $\alpha$ mRNA during DDR [121]. In response to UV radiation or hypoxic stress, hnRNP A18 is induced and has protective roles by increasing the expression of UV- or stress-response genes such as replication protein $A$ (RPA2), thioredoxin (TRX), or $H I F-1 \alpha[122,123]$. hnRNP A1 is reported to regulate alternative splicing of $h d m 2$ and UVE-triggered translation of Apaf-1 in response to UV exposure [124]. After ionizing radiation, hnRNP C has been found in DNA-damage sites and regulates BRCA gene expression and homologous recombination. Depletion of hnRNP C reduces the abundance of key HR proteins including BRCA1/2, RAD51, and BRIP1 by affecting alternative splicing [125]. hnRNP H/F is reported to increase after DNA damage and to enhance p53 expression by interfering 3 -end processing of $p 53 \mathrm{mRNA}$, thereby regulating apoptosis [126]. hnRNP I (also known as PTB) has been known to increase $H I F-1 \alpha$-mediated gene expression by enhancing translation of HIF-1 $\alpha$ in hypoxia [127].

3.1.3. FUS. FUS (also known as hnRNP P2) binds RNA and single- and double-stranded DNA, and it affects multiple steps of DNA/RNA metabolism. FUS has been observed in sites with laser-induced DNA double-strand breaks (DSBs) and regulates DSB repair [128]. FUS also has an important role in the DDR in neurons by directly interacting with histone deacetylase 1 (HDAC1), and recruitment of FUS and HDAC1 is essential for DDR signaling [129].

3.1.4. T Cell-Restricted Intracellular Antigens. $\mathrm{T}$ cellrestricted intracellular antigen-1 (TIA-1) is a member of RNA-binding protein involved in alternative pre-mRNA splicing and mRNA translation. TIA-1 is a component of stress granules (SGs) triggered by hypoxia, ischemia, and anoxia, and it has essential roles in regulating mRNAs involved in oxidative stress and DDR through its associations with other SG components [130]. A recent study has shown that TIA-1 oxidation, mediated by reactive oxygen species (ROS), suppresses SG formation and increases cell death after oxidative stress [131]. TIA-related protein (TIAR) has been reported to increase and regulate neuronal cell death after cerebral ischemic injury [132]. After UVC-induced DNA damage, TIAR is dissociated from C-rich motifcontaining mRNAs, including Apaf-1 mRNA, and enhances their translation [133].

3.1.5. Wig1. Wig1 (also known as ZMAT3) is a transcriptional target gene of p53 and has a zinc-finger domain that binds to double-strand RNA (dsRNA) [134]. Wig1 has been known to stabilize $p 53$ mRNA by protecting it from deadenylation, thereby enhancing the p53-mediated stress response [135]. Depletion of Wig1 is responsible for increases in cell death and cell-cycle arrest upon DNA damage. Wig1 functions as a survival factor during stress response by regulating FAS and 14-3-3 $\sigma$ [136].

\subsection{Cellular Senescence and Aging}

3.2.1. HuR. HuR is implicated in cellular senescence and the aging process based on its involvement in regulating stability and translation of various target mRNAs including $p 21, p 16$, cyclin A, cyclin B1, c-fos, and SIRT1 [137]. Recent reports have shown that loss of HuR is related to a shorter life span in Drosophila as well as to several senescence-associated phenotypes in mouse embryonic fibroblasts (MEF) [138, 139]. The HuR level is downregulated in RS and aging, and its expression is controlled by positive feedback mechanisms [140]. Coactivator-associated arginine methyltransferase 1 (CARM1) has been known as a regulator of HuR by inducing methylation on $\mathrm{R} 217$ residue of $\mathrm{HuR}$, and loss of CARM1 downregulates HuR activity in RS [141].

3.2.2. AU-Rich Element RNA-Binding Protein 1. AU-rich element RNA-binding protein 1 (AUF1; also known as hnRNP D) includes four alternative spliced isoforms (p37, p40, p42, and p45) containing two RRMs and regulates mRNA stability and turnover. In addition, AUF1 has been shown to affect proliferation, stress response, immune response, and cellular senescence. AUF1 is differentially regulated during aging and cellular senescence [140]. AUF regulates the mRNA stability of $p 21$ and $p 16$ in a competitive or cooperative manner with $\mathrm{HuR}$ and 


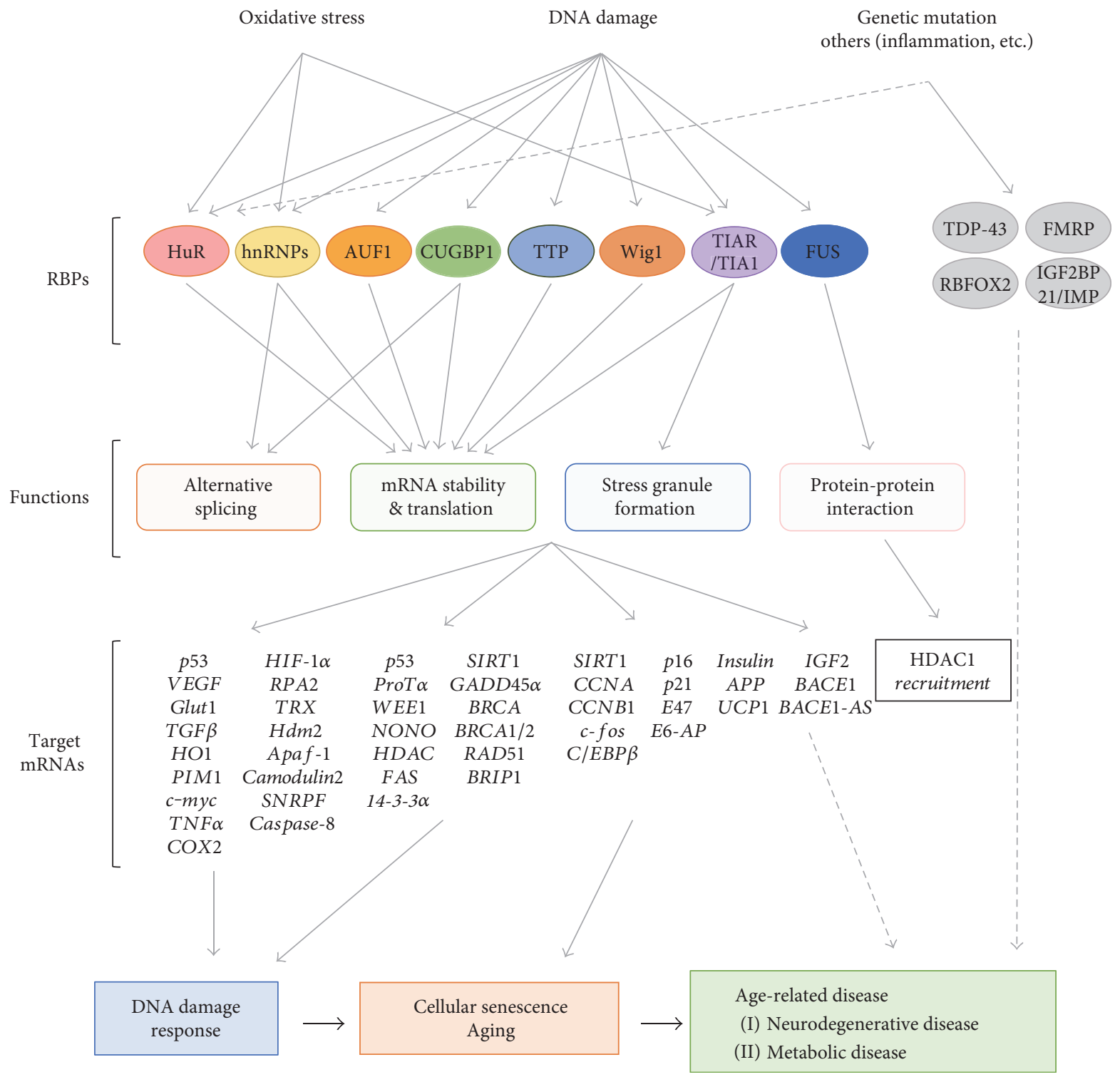

Figure 3: Representative RBPs involved in DNA damage and oxidative stress, cellular senescence, and age-related diseases.

influences cellular senescence $[142,143]$. Pont et al. reported that AUF1-deficient mice exhibit decreased telomerase level and activity, increased DNA damage at telomere ends, enhanced cellular senescence, and rapid premature aging [144].

3.2.3. TIA-1/TIAR. TIA-1 and TIAR regulate alternative splicing, SG formation, and translation of various target genes including TNF $\alpha, C O X-2, c-m y c$, calmodulin 2, small nuclear ribonucleoprotein polypeptide F (SNRPF), and caspase- 8 in response to various cellular stresses [145]. It has been shown that TIA-1 is downregulated during RS and aging [140]. TIA-1/TIAR depletion promotes cellular senescence of MEF cells [146]. However, the detailed mechanisms underlying TIA-1/TIAR-mediated regulation of cellular senescence or aging need to be elucidated.
3.2.4. CUGBP1. CUG triplet repeat, RNA-binding protein 1 (CUGBP1) is a member of the CELF/BRUNOL protein family containing two N-terminal RRMs and regulates premRNA alternative splicing, mRNA editing, and translation [147]. CUGBP1 has a role in enhancing p21 expression and regulates cellular senescence [148]. CUGBP1 binds to the $5^{\prime}$-UTR of $p 21$ and increases translation of $p 21$ by competing with calreticulin. In senescent cells, increased phosphorylation of CUGBP1 promotes binding to p21 mRNA.

CUGBP1 has been known to increase with aging in fat tissue and to regulate CCAAT/enhancer-binding protein $\beta(\mathrm{C} /$ $\operatorname{EBP} \beta$ ) expression [149]. CUGBP1 binds to $C / E B P \beta$ mRNA and enhances its translation, thereby accumulating $\mathrm{C} / \mathrm{EBP} \beta$ liver-enriched inhibitory protein $(\mathrm{C} / \mathrm{EBP} \beta$-LIP), a dominant inhibitor of differentiation, in fat cells. Augmented expression of CUGBP1 is responsible for the impairment of adipogenesis 
TABLE 1: A list of lncRNAs involved in DNA damage response, oxidative stress, cellular senescence, and age-related diseases.

\begin{tabular}{|c|c|c|}
\hline LncRNAs & Functions & References \\
\hline \multicolumn{3}{|c|}{ DNA damage response } \\
\hline LincRNA-p21 & Represses gene expression with hnRNP K & [20-22] \\
\hline LincRNA-RoR & $\begin{array}{l}\text { Suppresses p53 translation with hnRNP I and inhibits p53-mediated cell-cycle arrest } \\
\text { and apoptosis }\end{array}$ & [23-25] \\
\hline Pint & Connects p53 activation with epigenetic silencing by PRC2 & {$[20,26]$} \\
\hline PANDA & Regulates proapoptotic genes with NF-YA & [27-29] \\
\hline LncRNA-JADE & Connects the DNA damage response to histone $\mathrm{H} 4$ acetylation & {$[30]$} \\
\hline \multicolumn{3}{|l|}{ Oxidative stress } \\
\hline$H 19$ & Upregulated by oxidative stress & [31-34] \\
\hline ANRIL & Represses the expression of INK4A-ARF-INK4B & {$[35]$} \\
\hline LncRNA-LET & Degrades NF90 via ubiquitin-proteasome pathway & [36] \\
\hline$L I N K-A$ & Regulates the stabilization of HIF- $1 \alpha$ & [37] \\
\hline \multicolumn{3}{|l|}{ Cellular senescence } \\
\hline $7 S L$ & Promotes cell growth via suppression of $\mathrm{p} 53$ & {$[38,39]$} \\
\hline HOTAIR & Represses transcription of $\mathrm{HOXD}$ with $\mathrm{PRC} 2$ & [40-42] \\
\hline UCA1 & Negative correlation between p27 and UCA in breast cancer tissue & [43-45] \\
\hline LincRNA-p21 & Influences the p53 tumor suppressor pathway by regulating p53-mediated p 21 expression & {$[46]$} \\
\hline ANRIL & Regulates CDKN2A/B by epigenetic mechanisms & [47-52] \\
\hline ANRASSF1 & Represses the expression of RASSF1A & {$[53,54]$} \\
\hline PANDA & $\begin{array}{c}\text { Interacts with PRC1, PRC2, and NF-YA and represses the transcription of senescence-promoting } \\
\text { genes }\end{array}$ & {$[55,56]$} \\
\hline FAL1 & Oncogenic activity of FAL1 is repression of p21 & {$[57,58]$} \\
\hline MIR31HG & Interacts with both INK3A and $\mathrm{PcG}$ proteins and represses INK4A & {$[59]$} \\
\hline SALNR & Regulates NF90 activity & {$[60]$} \\
\hline$V A D$ & Regulates chromatin structure and increases the expression of INK4 & {$[61]$} \\
\hline \multicolumn{3}{|c|}{ Neurodegenerative diseases } \\
\hline BC200 & Upregulation of $\mathrm{BC} 200$ related to the severity of $\mathrm{AD}$ & {$[63,64]$} \\
\hline$B A C E 1-A S$ & Regulates BACE1 mRNA and generates $\mathrm{A} \beta 1-42$ & {$[65,66]$} \\
\hline NDM29 & Induces $\mathrm{APP}$ and increases $\mathrm{A} \beta$ secretion & {$[67,68]$} \\
\hline $17 A$ & Enhances $\mathrm{A} \beta$ secretion by impairing GABA-B signaling & {$[69,71]$} \\
\hline AS Uchl1 & Induces Uchl1 expression by increasing its translation & {$[73]$} \\
\hline naPINK1 & Regulates the stabilization of svPINK1 expression & {$[71,74]$} \\
\hline TUG1 & Downstream target of p53 and regulates cell-cycle genes & [76-79] \\
\hline MEG3 & Epigenetically regulates chromatin in $\mathrm{HD}$ & {$[16,78]$} \\
\hline HTTAS-V1 & Overexpression of HTTAS-V1 reduces HTT transcripts & {$[80]$} \\
\hline \multicolumn{3}{|l|}{ Immune response } \\
\hline THRIL & $\begin{array}{c}\text { Regulates TNF } \alpha \text { expression and is associated with childhood acute inflammatory } \\
\text { diseases }\end{array}$ & {$[82]$} \\
\hline $\operatorname{Lnc}-D C$ & Exclusively expressed in dendritic cells and regulates DC differentiation & {$[83]$} \\
\hline$L n c-I L 7 R$ & Diminishes LPS-induced inflammatory response & {$[84]$} \\
\hline LincRNA-EPS & Regulated in macrophages to control the expression of immune response genes & [85] \\
\hline \multicolumn{3}{|l|}{ Diabetes } \\
\hline RNCR3 & Regulates retinal endothelial cell function via RNCR3/KLF2/miR-185-5p & {$[87,88]$} \\
\hline MEG3 & Downregulates MEG3 in the retinas of STZ-induced diabetic mice & {$[89,90]$} \\
\hline HI-LNC25 & Regulates $\beta$ cell differentiation and maturation & {$[91,92]$} \\
\hline \multicolumn{3}{|l|}{ Muscle dysfunction } \\
\hline$S R A$ & Enhances the activity of nuclear receptors and regulates differentiation of MyoD & {$[94,95]$} \\
\hline MUNC & Facilitates the function of MyoD in skeletal myogenesis & [96] \\
\hline
\end{tabular}


TABLE 1: Continued.

\begin{tabular}{lcc}
\hline LncRNAs & Functions & References \\
\hline $\begin{array}{l}\text { Linc-RAM } \\
\text { Atherosclerosis }\end{array}$ & Promotes assembly of MyoD-Baf60-Brg1 complex and increases the transcription of \\
myogenic differentiation genes
\end{tabular}

in aged-fat tissues. In old liver, CUGBP1 phosphorylation at S302 residue by GSK $3 \beta$ facilitates the association of CUGBP1 with eukaryotic initiation factor 2 (eIF2) and increases translation of $H D A C 1$ and $C / E B P \beta$, which are responsible for epigenetic regulation of gene expression [150, 151].

3.2.5. Tristetraprolin. Tristetraprolin (TTP) is an AREbinding protein involved in destabilizing target mRNAs, and its expression is upregulated during cellular senescence and aging [152]. TTP is elevated in B lymphocytes from aged mice compared to the level in cells from young mice, and it destabilizes transcription factor E47 mRNA [153]. Sanduja et al. have reported that TTP promotes cellular senescence by destabilizing E6-AP ubiquitin ligase mRNA [154]. E6AP downregulation mediated by TTP results in p53 and hTERT accumulation in cells.

3.2.6. Wig1. Wig1 is also implicated in the regulation of cellular senescence. Kim et al. reported that Wig1 prevents cellular senescence by regulating p21 expression [155]. Wig1 binds to the stem-loop structure near the miRNAbinding site of $p 21 \mathrm{mRNA}$ and recruits the RNA-induced silencing complex (RISC) by interacting with Ago2, thereby destabilizing p21 mRNA. Depletion of Wig1 results in a decrease of miR-mediated p21 mRNA decay and promotes cellular senescence via p21 upregulation in various cell types.

\subsection{Age-Related Diseases}

3.3.1. Neurodegenerative Diseases. Neuronal cells have their own systems for regulating RNA expression in response to various stimuli via RBPs that are uniquely expressed in neuronal cells. Accumulating evidence indicates that abnormalities in RNA metabolism are a common feature of neurodegeneration [156, 157]. Therefore, mutations or dysregulation of RBPs is widely involved in the pathogenesis of neurodegenerative diseases, including amyotrophic lateral sclerosis, AD, $\mathrm{HD}$, and PD, by governing RNA metabolism [158].

(1) TDP-43. TDP-43 was identified as the major component of ubiquitin-positive neuronal inclusion bodies observed in amyotrophic lateral sclerosis (ALS) and frontotemporal lobar degeneration (FTLD) patients [159]. TDP-43 functions as a translational repressor and known to have essential roles in transcriptional regulation and miRNA maturation [160]. Also, TDP-43 regulates axonal transport of RNA granules by interacting with hnRNP A2/B1 [161, 162]. Mutations of TDP-43 genes found in ALS patients are related to delocalization and aggregation of TDP-43. Formation of insoluble aggregates of TDP-43 in the cytoplasm alters interactions between TDP-43 and its target mRNAs having important functions in the brain, thereby indicating the involvement of TDP-43 in ALS/FTLD pathogenesis [163].

(2) FUS. Mutations in the gene coding FUS are found in 5\% of familial ALS patients and in rare sporadic cases. Like TDP-43, mutations on FUS gene facilitate delocalization and abnormal aggregation of FUS to cytoplasm and affect the alternative splicing of its target genes [164, 165]. Also, FUS mutations are responsible for an increase in DNA damage in ALS patients [129].

(3) $\mathrm{HuD}$. HuD (also known as nELAVL or ELAVL4) is expressed in the brain and has been implicated in various aspects of RNA metabolism [166]. HuD functions as a pivotal regulator of neurogenesis, axonal growth, and neuronal function, and dysregulation of $\mathrm{HuD}$ results in neuronal defects [167]. HuD has been reported to increase in the brain of $\mathrm{AD}$ patients and to stabilize $A P P$ mRNA, $\beta$-site $A P P$ cleaving enzyme 1 (BACE1) mRNA, and BACE1 antisense (BACE1-AS) lncRNAs, thereby facilitating the accumulation of the toxic APP cleavage product $\mathrm{A} \beta$ [168].

(4) FMRP. Fragile X mental retardation protein (FMRP) is a gene product encoded by fragile $\mathrm{X}$ mental retardation 1 (FMR1) and plays essential roles in normal cognitive development and female reproductive function [169]. Mutations on the FXR1 gene lead to fragile X syndrome (FXS), autism, $\mathrm{AD}$, and $\mathrm{PD}$ by dysregulating translation of its target genes [170]. FMRP inhibits $A P P$ mRNA translation by recruiting APP mRNA into P-bodies [171]. FMRP has been shown to decrease in the brain of sporadic AD patients [172].

(5) hnRNPs. hnRNP A1 has essential roles in the regulation of pre-mRNA processing, transport, and translation of mRNAs [173]. Loss of hnRNP A1 expression or presences of mutations (D262) are observed in ALS patients [162]. In addition, hnRNP A1 shows a decrease in the AD brain and has been known to regulate alternative splicing of $R A G E$ and $A P P$ mRNAs $[174,175]$.

hnRNP A2/B1 affects alternative splicing of ALSassociated D-amino acid oxidase, and ALS mutant (hnRNP 
TABLE 2: A list of RBPs involved in DNA damage response, oxidative stress, cellular senescence, and age-related diseases.

\begin{tabular}{|c|c|c|}
\hline RBPs & Functions & References \\
\hline \multicolumn{3}{|c|}{ DNA damage response and oxidative stress } \\
\hline HuR & $\begin{array}{l}\text { Protection roles in oxidative stress and DNA damage by regulating RNA metabolism } \\
\text { (reviewed in 114,115) } \\
\text { Regulates HO1, WEE1, and NONO expression during stress response }\end{array}$ & {$[114-119]$} \\
\hline hnRNP A0 & Phosphorylation of hnRNP A0 by MK2 promotes GADD $45 \alpha$ mRNA stabilization & {$[121]$} \\
\hline hnRNP A18 & Increases gene expression involved in stress-response & {$[122,123]$} \\
\hline hnRNP A1 & Involved in alternative splicing of $h d m 2$ and Apaf- 1 translation & {$[124]$} \\
\hline hnRNP C & Regulates BRCA gene expression and homologous recombination after ionizing irradiation & {$[125]$} \\
\hline hnRNP H/F & Increased in DNA damage response and upregulates p53 expression & {$[126]$} \\
\hline hnRNP I & Enhances translation of $H I F-1 \alpha$ in hypoxia & {$[127]$} \\
\hline FUS & Interacts with $\mathrm{HDAC} 1$ and regulates DNA damage response & [129] \\
\hline TIA-1/TIAR & $\begin{array}{l}\text { TIA-1/TIAR are involved in SG formation after stress response and decrease } H I F-1 \alpha \\
\text { translation } \\
\text { TIA-1 oxidation by ROS suppresses SG formation and increases cell death } \\
\text { TIAR increases Apaf- } 1 \text { translation after UVC-induced DNA damage }\end{array}$ & {$[130,131,133]$} \\
\hline Wig1 & Stabilizes $p 53 \mathrm{mRNA}$ and enhancing p53-mediated stress response & {$[136]$} \\
\hline \multicolumn{3}{|c|}{ Cellular senescence and aging } \\
\hline HuR & $\begin{array}{l}\text { HuR loss is related to shorter life span and enhanced senescence-associated phenotypes } \\
\text { (reviewed in 137) } \\
\text { CARM1 downregulates HuR activity in replicative senescence }\end{array}$ & {$[137-139,141]$} \\
\hline AUF1 & $\begin{array}{l}\text { Involved in cellular senescence by regulating mRNA stability of } p 21 \text { and } p 16 \text {, and AUF1 } \\
\text { KO mice show enhanced cellular senescence and rapid premature aging }\end{array}$ & {$[142-144]$} \\
\hline TIA-1/TIAR & $\begin{array}{l}\text { Down-regulated in cellular senescence and TIA-1/TIAR depletion promotes cellular senescence } \\
\text { of MEF cells }\end{array}$ & {$[140,146]$} \\
\hline CUGBP1 & $\begin{array}{l}\text { CUGBP1 phosphorylation promotes the binding to } p 21 \text { mRNA in senescent cells } \\
\text { Regulates C/EBP } \beta \text { and HDAC } 1 \text { in the liver and fat of old mice }\end{array}$ & {$[148,150,151]$} \\
\hline TTP & $\begin{array}{l}\text { Upregulated in senescent cells and contributes to p53 accumulation by destabilizing } \\
\qquad E 6-A P \text { mRNA }\end{array}$ & {$[140,154]$} \\
\hline Wig1 & Prevents premature senescence by destabilizing $p 21$ mRNA & {$[155]$} \\
\hline \multicolumn{3}{|c|}{ Neurodegenerative diseases } \\
\hline TDP-43 & $\begin{array}{l}\text { Functions as a translational repressor } \\
\text { Regulates axonal transport of RNA granules by interacting with hnRNP A2/B1 } \\
\text { Mutants form of TDP-43 found in ALS patients are prone to aggregation }\end{array}$ & {$[160-162]$} \\
\hline FUS & $\begin{array}{l}\text { Interacts with DNA/RNA and regulates DNA/RNA metabolism } \\
\text { Mutation found in ALS patients are related to abnormal aggregation of FUS in cytoplasm } \\
\text { and dysregulation of alternative splicing }\end{array}$ & {$[164]$} \\
\hline $\mathrm{HuD}$ & $\begin{array}{l}\text { Has pivotal roles in neurogenesis, axonal growth, and neuronal functions } \\
\text { Upregulated in the brain of } \mathrm{AD} \text { patients and promotes } \mathrm{A} \beta \text { accumulation }\end{array}$ & {$[166,168]$} \\
\hline FMRP & $\begin{array}{c}\text { Mutations on FXP1 gene are linked to FXS, } \mathrm{AD} \text {, and } \mathrm{PD} \text { by dysregulation translation of } \\
\text { target genes } \\
\text { Downregulated in the brain of sporadic AD patients and regulates APP translation }\end{array}$ & {$[170-172]$} \\
\hline hnRNP A1 & $\begin{array}{l}\text { Loss of hnRNP A1 or mutations on D262 residue is found in the ALS patients } \\
\text { Downregulated in the brain of AD patients and affects to splicing of RAGE and APP mRNAs }\end{array}$ & {$[174,175]$} \\
\hline hnRNP A2/B1 & $\begin{array}{l}\text { Mutation on D290 residue dysregulates cellular stress response in ALS } \\
\text { Differentially expressed in the brain of AD and affects alternative splicing }\end{array}$ & {$[176,177]$} \\
\hline hnRNP C & $\begin{array}{l}\text { Upregulated in the brain of AD patients } \\
\text { Stabilizes } A P P \text { mRNA and enhances translation of } A P P\end{array}$ & {$[171,172]$} \\
\hline \multicolumn{3}{|l|}{ Metabolic diseases } \\
\hline $\mathrm{HuD}$ & $\begin{array}{l}\text { Downregulated in the pancreas of T2DM } \\
\text { Regulates insulin biosynthesis, autophagosome formation, lipid synthesis, and apoptosis } \\
\text { in pancreatic } \beta \text { cells }\end{array}$ & {$[181-184]$} \\
\hline
\end{tabular}


TABLE 2: Continued.

\begin{tabular}{lcc}
\hline RBPs & Functions & References \\
\hline CUGBP1 & Upregulated in the diabetic hearts and the pancreas and regulates insulin secretion and \\
insulin resistance & Obesity-related SNPs on CUGBP1 influence alternative splicing, translation, and \\
turnover of target mRNAs & Plays essential roles in alternative splicing \\
RBFOX2 & In diabetic hearts, majority of misspliced transcripts have RBFOX2-binding sites \\
IGF2BP2/IMP & SNPs on IGF2BP2/IMP2 genes are associated to T2DM \\
\hline
\end{tabular}

A2B1 D290V) dysregulates cellular stress responses [162, 176]. hnRNP A2/B1 and hnRNP B1 are also differentially expressed in the AD brain [177].

hnRNP $\mathrm{C}$ has been known to stabilize APP mRNA or enhance its translation by competing with FMRP, therefore positively regulates APP expression [171]. Borreca et al. reported augmented expression of hnRNP $\mathrm{C}$ in the brain of sporadic AD patients [172].

3.3.2. Metabolic Diseases. Metabolic disease is associated with the risk of developing T2DM, obesity, cardiovascular disease (CVD), and coronary heart disease (CHD) [178, 179]. Increasing evidence indicates that dysregulation of RNA metabolism in metabolically active and insulin-sensitive organs, such as the pancreas, liver, muscle, and adipose tissues, is actively implicated in the pathogenesis of metabolic diseases [180].

(1) $\mathrm{HuD} . \mathrm{HuD}$ is also found in the islets of the pancreas and mediates RNA quality control of pancreatic $\beta$ cells [181]. In the pancreatic islets of a T2DM mouse model, HuD expression is downregulated [163]. HuD regulates insulin biosynthesis by associating with $5^{\prime}$-UTR of insulin 2 mRNA and repressing its translation [181]. In addition, $\mathrm{HuD}$ regulates autophagosome formation and lipid synthesis via translation regulation of ATG5 and INSIG1, respectively $[182,183]$. Moreover, $\mathrm{HuD}$ regulates apoptosis of pancreatic $\beta$ cells [184].

(2) CUGBP1. CUGBP1 has been reported to regulate insulin resistance and alternative splicing of the insulin [185]. In addition, CUGBP1 negatively regulates insulin secretion by stabilizing phosphodiesterase subtype 3B (PDE3B) [186]. CUGBP1 expression is higher in diabetic heart and pancreas, and single nucleotide polymorphisms (SNPs) on the CUGBP1 locus are associated with obesity [186, 187].

(3) RBFOX2. RBFOX2 (also known as RBM9) is a RNAbinding protein and a homolog of $C$. elegans Fox-1 and regulates alternative splicing by directly binding to the consensus (U)GCAUG motif in the target pre-mRNAs [188]. A recent study by Nutter et al. showed that $73 \%$ of transcripts misspliced in diabetic hearts have RBFOX2-binding sites, and a dominant negative form of RBFOX2 (DN-RBFOX2) was found in diabetic hearts [189]. DN-RBFOX2 precedes diabetic cardiac complications, as well as delays intracellular calcium transients in cardiomyocytes by blocking RBFOX2mediated alternative splicing.

(4) IGF2BP2/IMP2. Insulin-like growth factor 2 mRNAbinding protein 2 (IGF2BP2/IMP2) belongs to IGF2 mRNA-binding protein (IMP) family and is known to regulate IGF2 translation by interacting with the $5^{\prime}$-UTR of IGF2 mRNA [190]. Genome-wide association studies have shown that the human IGF2BP/IMP2 gene contains SNPs associated with T2DM [191, 192]. Dai et al. demonstrated that mice lacking IGF2BP2/IMP2 resist diet-induced obesity and have improved glucose tolerance, insulin sensitivity, and longer lifespan through the increased translation of UCP1 or mitochondrial components [193].

Representative RBPs involved in DNA damage and oxidative stress, cellular senescence, and age-related diseases are shown in Figure 3.

\section{Conclusion}

Increasing evidence indicates that ncRNAs and RBPs are essential regulators of various cellular processes, and dysregulation of these RNA regulators is implicated in the pathogenesis of several diseases including neurodegenerative diseases, metabolic diseases, and cancer. In this review, we tried to discuss the regulatory lncRNAs and RBPs that are involved in stress response, cellular senescence, and the pathogenesis of age-related diseases including neurodegenerative diseases, metabolic diseases, immune response, and muscle dysfunction (Tables 1 and 2). We have limited our discussion to lncRNAs and RBPs because miRNAs have been intensively reviewed by others [194-196]. Although the list of reviewed lncRNAs and RBPs is extensive, additional RNA regulators are certainly going to be uncovered in future studies of stress-related responses and age-related diseases.

The results of studies undertaken to uncover the roles of lncRNAs and RBPs during stress response, cellular senescence, and the pathogenesis of age-related diseases are prompting several questions for immediate consideration. For example, what are the molecular targets of lncRNAs and RBPs? What signaling pathways control the expression and function of lncRNAs and RBPs during the stress response or in the pathogenesis of age-related diseases? How do they contribute to the stress response and cellular senescence? Do lncRNAs and RBPs interplay in order to fine tune RNA metabolism? How are RNA regulators including 
IncRNAs, miRNAs, and RBPs differentially expressed in agerelated diseases? As we begin to consider these questions, the importance of functional networking between RBPs and ncRNAs is coming to the forefront [197-199].

A deeper and more comprehensive knowledge of the fine mechanisms involving lncRNAs and RBPs in the regulation of RNA metabolism is warranted because regulatory lncRNAs and RBPs are promising novel targets for intervention in physiopathologies with underlying deficiencies in stress response, cellular senescence, and the aging process.

\section{Conflicts of Interest}

The authors declare that they have no competing interests.

\section{Authors' Contributions}

Chongtae Kim and Donghee Kang equally contributed to this work.

\section{Acknowledgments}

This work was supported by grants awarded to Jae-Seon Lee from the Basic Science Research Program (no. 2014R1A2A1A11051988), Nuclear Research and Development Program (no. 2012-M2B2B1-2012055637), and Medical Research Center (MRC) (no. 201409392). Eun Kyung Lee and Chongtae Kim are supported by the National Research Foundation of Korea (NRF) (2014R1A2A1A11053431 and 2016R1A6A3A11931343).

\section{References}

[1] J. Campisi, “Aging, cellular senescence, and cancer," Annual Review of Physiology, vol. 75, pp. 685-705, 2013.

[2] L. Hayflick and P. S. Moorehead, "The serial cultivation of human diploid cell strains," Experimental Cell Research, vol. 25, no. 3, pp. 585-621, 1961.

[3] I. Ben-Porath and R. A. Weinberg, "The signals and pathways activating cellular senescence," The International Journal of Biochemistry and Cell Biology, vol. 37, no. 5, pp. 961-976, 2005.

[4] P. Davalli, T. Mitic, A. Caporali, A. Lauriola, and D. D’Arca, "ROS, cell senescence, and novel molecular mechanisms in aging and age-related diseases," Oxidative Medicine and Cellular Longevity, vol. 2016, Article ID 3565127, 18 pages, 2016.

[5] J.-P. Coppé, C. K. Patil, F. Rodier et al., "Senescenceassociated secretory phenotypes reveal cell-nonautonomous functions of oncogenic RAS and the p53 tumor suppressor," PLoS Biology, vol. 6, no. 12, article e301, 2008.

[6] M. Lee and J.-S. Lee, "Exploiting tumor cell senescence in anticancer therapy," Biochemistry and Molecular Biology Reports, vol. 47, no. 2, pp. 51-59, 2014.

[7] J. W. Shay and I. B. Roninson, "Hallmarks of senescence in carcinogenesis and cancer therapy," Oncogene, vol. 23, no. 16, pp. 2919-2933, 2004.

[8] D. Muñoz-Espín and M. Serrano, "Cellular senescence: from physiology and pathology," Nature Review Molecular Cell Biology, vol. 15, no. 7, pp. 482-496, 2014.
[9] C. López-Otín, M. A. Blasco, L. Partridge, M. Serrano, and G. Kroemer, "The hallmarks of aging," Cell, vol. 153, no. 6, pp. 1194-1217, 2013.

[10] B. G. Childs, M. Durik, D. J. Baker, and J. M. van Deursen, "Cellular senescence in aging and age-related diseases: from mechanisms to therapy," Nature Medicine, vol. 21, no. 12, pp. 1424-1435, 2015.

[11] M. I. Christmann and B. Kaina, "Transcriptional regulation of human DNA repair genes following genotoxic stress: trigger mechanisms, inducible responses and genotoxic adaptation," Nucleic Acids Research, vol. 41, no. 18, pp. 8403-8420, 2013.

[12] F. Lanigan, J. G. Geraghty, and A. P. Bracken, "Transcriptional regulation of cellular senescence," Oncogene, vol. 30, pp. 2901-2911, 2011.

[13] X. Chen, Y. Zhang, H. Xu, and G. Bu, "Transcriptional regulation and its misregulation in Alzheimer's disease," Molecular Brain, vol. 6, p. 44, 2013.

[14] B. Desvergne, L. Michalik, and W. Wahli, "Transcriptional regulation of metabolism," Physiological Reviews, vol. 88, no. 2, pp. 465-514, 2006.

[15] I. Grammatikakis, A. C. Panda, K. Abdelmohsen, and M. Gorospe, "Long noncoding RNAs (lncRNAs) and the molecular hallmarks of aging," Aging (Albany NY), vol. 6, no. 12, pp. 992-1009, 2014.

[16] S. Kour and P. C. Rath, "Long noncoding RNAs in aging and age-related diseases," Ageing Research Reviews, vol. 26, pp. 1-21, 2016.

[17] A. M. Schmitt and H. Y. Chang, "Long noncoding RNAs in cancer pathways," Cancer Cell, vol. 29, no. 4, pp. 452-463, 2016.

[18] J. R. Prensner and A. M. Chinnaiyan, "The emergence of lncRNAs in cancer biology," Cancer Discovery, vol. 1, no. 5, pp. 391-407, 2011.

[19] M. Montes and A. H. Lund, "Emerging roles of lncRNAs in senescence," The FEBS Journal, vol. 283, no. 13, pp. 2414-2426, 2016.

[20] M. Huarte, M. Guttman, D. Feldser et al., "A large intergenic noncoding RNA induced by p53 mediates global gene repression in the p53 response," Cell, vol. 142, no. 3, pp. 409-419, 2010.

[21] F. Yang, H. Zhang, Y. Mei, and M. Wu, "Reciprocal regulation of HIF- $1 \alpha$ and lincRNA-p21 modulates the Warburg effect," Molecular Cell, vol. 53, no. 1, pp. 88-100, 2014.

[22] J. R. Hall, Z. J. Messenger, H. W. Tam, S. L. Phillips, L. Recio, and R. C. Smart, "Long noncoding RNA lincRNA-p21 is the major mediator of UVB-induced and p53-dependent apoptosis in keratinocytes," Cell Death and Diseases, vol. 6, article e1700, 2015.

[23] S. Loewer, M. N. Cabili, M. Guttman et al., "Long intergenic non-coding RNA-RoR modulates reprogramming of human diploid pluripotent stem cells," Nature Genetics, vol. 42, no. 12, pp. 1113-1117, 2010.

[24] A. Zhang, N. Zhou, J. Huang et al., "The human long non-coding RNA-RoR is a p53 repressor in response to DNA damage," Cell Research, vol. 23, no. 3, pp. 340-350, 2013.

[25] J. Fan, Y. Xing, X. Wen et al., "Long non-coding RNA ROR decoys gene-specific histone methylation to promote tumorigenesis," Genome Biology, vol. 16, p. 139, 2015.

[26] O. Marín-Béjar, F. P. Marchese, A. Athie et al., "Pint lincRNA connects the p53 pathway with epigenetic silencing by the 
Polycomb repressive complex 2," Genome Biology, vol. 14, no. 9, article R104, 2013.

[27] T. Hung, Y. Wang, M. F. Lin et al., "Extensive and coordinated transcription of noncoding RNAs within cell-cycle promoters," Nature Genetics, vol. 43, no. 7, pp. 621-629, 2011.

[28] Y. Kotake, K. Kitagawa, T. Ohhata et al., "Long non-coding RNA, PANDA, contributes to the stabilization of p53 tumor suppressor protein," Anticancer Research, vol. 36, no. 4, pp. 1605-1611, 2016.

[29] Y. Kotake, T. Goto, M. Naemura, Y. Inoue, H. Okamoto, and K. Tahara, "Long noncoding RNA PANDA positively regulates proliferation of osteosarcoma cells," Anticancer Research, vol. 37, no. 1, pp. 81-85, 2017.

[30] G. Wan, X. Hu, Y. Liu et al., "A novel non-coding RNA lncRNA-JADE connects DNA damage signaling to histone H4 acetylation," The EMBO Journal, vol. 32, no. 21, pp. 2833-2847, 2013.

[31] I. Matouk, E. Raveh, P. Ohana et al., "The increasing complexity of the oncofetal h19 gene locus: functional dissection and therapeutic intervention," International Journal of Molecular Science, vol. 14, no. 2, pp. 4298-4316, 2013.

[32] I. J. Matouk, S. Mezan, A. Mizrahi et al., "The oncofetal H19 RNA connection: hypoxia, p53 and cancer," Biochimica et Biophysica Acta, vol. 1803, no. 4, pp. 443-451, 2010.

[33] O. Ravid, O. Shoshani, M. Sela et al., "Relative genomic stability of adipose tissue derived mesenchymal stem cells: analysis of ploidy, H19 long non-coding RNA and p53 activity," Stem Cell Research and Therapy, vol. 5, no. 6, p. 139, 2014.

[34] X. Li, H. Wang, B. Yao, W. Xu, J. Chen, and X. Zhou, "IncRNA H19/miR-675 axis regulates cardiomyocyte apoptosis by targeting VDAC1 in diabetic cardiomyopathy," Scientific Reports, vol. 6, article 36340, 2016.

[35] G. Wan, R. Mathur, X. Hu et al., "Long non-coding RNA ANRIL(CDKN2B-AS) is induced by the ATM-E2F1 signaling pathway," Cellular Signalling, vol. 25, no. 5, pp. 1086-1095, 2013.

[36] F. Yang, X. S. Huo, S. X. Yuan et al., "Repression of the long noncoding RNA-LET by histone deacetylase 3 contributes to hypoxia-mediated metastasis," Molecular Cell, vol. 49, no. 6, pp. 1083-1096, 2013.

[37] A. Lin, C. Li, Z. Xing et al., "The LINK-A lncRNA activates normoxic HIF1 $\alpha$ signaling in triple-negative breast cancer," Nature Cell Biology, vol. 18, no. 2, pp. 213-224, 2016.

[38] P. Walter and G. Blobel, "Signal recognition particle contains a 7S RNA essential for protein translocation across the endoplasmic reticulum," Nature, vol. 299, no. 5885, pp. 691-698, 1982.

[39] K. Abdelmohsen, A. C. Panda, M. J. Kang et al., "7SL RNA represses p53 translation by competing with HuR," Nucleic Acids Research, vol. 42, no. 15, pp. 10099-10111, 2014.

[40] J. L. Rinn, M. Kertesz, J. K. Wang et al., "Functional demarcation of active and silent chromatin domains in human HOX loci by noncoding RNAs," Cell, vol. 129, no. 7, pp. 13111323, 2007.

[41] R. A. Gupta, N. Shah, K. C. Wang et al., "Long non-coding RNA HOTAIR reprograms chromatin state to promote cancer metastasis," Nature, vol. 464, no. 7291, pp. 1071-1076, 2010.

[42] A. R. Özeş, D. F. Miller, O. N. Özeş et al., "NF- $\kappa$ B-HOTAIR axis links DNA damage response, chemoresistance and cellular senescence in ovarian cancer," Oncogene, vol. 35, no. 41 , pp. 5350-5361, 2016.
[43] F. Wang, X. Li, X. Xie, L. Zhao, and W. Chen, "UCA1, a non-protein-coding RNA up-regulated in bladder carcinoma and embryo, influencing cell growth and promoting invasion," The FEBS Journal, vol. 582, no. 13, pp. 19191927, 2008.

[44] P. P. Kumar, U. Emechebe, R. Smith et al., "Coordinated control of senescence by lncRNA and a novel T-box3 co-repressor complex," eLife, vol. 3, 2014.

[45] J. Huang, N. Zhou, K. Watabe et al., "Long non-coding RNA UCA1 promotes breast tumor growth by suppression of p27 (Kip1)," Cell Death and Disease, vol. 5, article e1008, 2014.

[46] N. Dimitrova, J. R. Zamudio, R. M. Jong et al., "LincRNA-p21 activates p21 in cis to promote Polycomb target gene expression and to enforce the G1/S checkpoint," Molecular Cell, vol. 54, no. 5, pp. 777-790, 2014.

[47] E. Pasmant, I. Laurendeau, D. Héron, M. Vidaud, D. Vidaud, and I. Bièche, "Characterization of a germ-line deletion, including the entire INK4/ARF locus, in a melanomaneural system tumor family: identification of ANRIL, an antisense noncoding RNA whose expression coclusters with ARF," Cancer Research, vol. 67, no. 8, pp. 3963-3969, 2007.

[48] K. L. Yap, S. Li, A. M. Muñoz-Cabello et al., "Molecular interplay of the noncoding RNA ANRIL and methylated histone $\mathrm{H} 3$ lysine 27 by polycomb CBX7 in transcriptional silencing of INK4a," Molecular Cell, vol. 38, no. 5, pp. 662-674, 2010.

[49] Y. Kotake, T. Nakagawa, K. Kitagawa et al., "Long noncoding RNA ANRIL is required for the PRC2 recruitment to and silencing of p15(INK4B) tumor suppressor gene," Oncogene, vol. 30, no. 16, pp. 1956-1962, 2011.

[50] J. J. Qiu, Y. Wang, Y. L. Liu, Y. Zhang, J. X. Ding, and K. Q. Hua, "The long non-coding RNA ANRIL promotes proliferation and cell cycle progression and inhibits apoptosis and senescence in epithelial ovarian cancer," Oncotarget, vol. 7, no. 22, pp. 32478-32492, 2016.

[51] F. Q. Nie, M. Sun, J. S. Yang et al., "Long noncoding RNA ANRIL promotes non-small cell lung cancer cell proliferation and inhibits apoptosis by silencing KLF2 and P21 expression," Molecular Cancer Therapeutics, vol. 14, no. 1, pp. 268-277, 2015.

[52] F. Aguilo, M. M. Zhou, and M. J. Walsh, "Long noncoding RNA, polycomb, and the ghosts haunting INK4b-ARFINK4a expression," Cancer Research, vol. 71, no. 16, pp. 5365-5369, 2011.

[53] F. C. Beckedorff, A. C. Ayupe, R. Crocci-Souza et al., "The intronic long noncoding RNA ANRASSF1 recruits PRC2 to the RASSF1A promoter, reducing the expression of RASSF1A and increasing cell proliferation," PLoS Genetics, vol. 9, no. 8, article e1003705, 2013.

[54] S. Thaler, P. S. Hähnel, A. Schad, R. Dammann, and M. Schuler, "RASSF1A mediates p21Cip1/Waf1-dependent cell cycle arrest and senescence through modulation of the Raf-MEK-ERK pathway and inhibition of Akt," Cancer Research, vol. 69, no. 5, pp. 1748-1757, 2009.

[55] P. K. Puvvula, R. D. Desetty, P. Pineau et al., "Long noncoding RNA PANDA and scaffold-attachment-factor SAFA control senescence entry and exit," Nature Communications, vol. 5, p. 5323, 2014.

[56] R. Helbig and F. O. Fackelmayer, "Scaffold attachment factor A (SAF-A) is concentrated in inactive $\mathrm{X}$ chromosome territories through its RGG domain," Chromosoma, vol. 112, no. 4, pp. 173-182, 2003. 
[57] X. Zhong, X. Hu, and L. Zhang, "Oncogenic long noncoding RNA FAL1 in human cancer," Molecular and Cellular Oncology, vol. 2, no. 2, article e977154, 2015.

[58] X. Hu, Y. Feng, D. Zhang et al., "A functional genomic approach identifies FAL1 as an oncogenic long noncoding RNA that associates with BMI1 and represses p21 expression in cancer," Cancer Cell, vol. 26, no. 3, pp. 344-357, 2014.

[59] M. Montes, M. M. Nielsen, G. Maglieri et al., "The lncRNA MIR31HG regulates p16(INK4A) expression to modulate senescence," Nature Communications, vol. 6, p. 6967, 2015.

[60] C. L. Wu, Y. Wang, B. Jin, H. Chen, B. S. Xie, and Z. B. Mao, "Senescence-associated long non-coding RNA (SALNR) delays oncogene-induced senescence through NF90 regulation," The Journal of Biological Chemistry, vol. 290, no. 50, pp. 30175-30192, 2015.

[61] S. Lazorthes, B. Vallot, S. Briois et al., "A vlincRNA participates in senescence maintenance by relieving H2AZmediated repression at the INK4 locus," Nature Communications, vol. 6, p. 5971, 2015.

[62] C. Ballard, S. Gauthier, A. Corbett, C. Brayne, D. Aarsland, and E. Jones, "Alzheimer's disease," Lancet, vol. 377, no. 9770, pp. 1019-1031, 2011.

[63] H. Tiedge, W. Chen, and J. Brosius, "Primary structure, neural-specific expression, and dendritic location of human BC200 RNA," Journal of Neuroscience, vol. 13, no. 6, pp. 2382-2390, 1993.

[64] E. Mus, P. R. Hof, and H. Tiedge, "Dendritic BC200 RNA in aging and in Alzheimer's disease," Proceedings of the National Academy of Sciences of the United States of America, vol. 104, no. 25, pp. 10679-10684, 2007.

[65] M. A. Faghihi, F. Modarresi, A. M. Khalil et al., "Expression of a noncoding RNA is elevated in Alzheimer's disease and drives rapid feed-forward regulation of $\beta$-secretase expression," Nature Medicine, vol. 14, no. 7, pp. 723-730, 2008.

[66] F. Modarresi, M. A. Faghihi, N. S. Patel, B. G. Sahagan, C. Wahlestedt, and M. A. Lopez-Toledano, "Knockdown of BACE1-AS nonprotein-coding transcript modulates betaamyloid-related hippocampal neurogenesis," International Journal of Alzheimer's Disease, vol. 2011, Article ID 929042, 11 pages, 2011.

[67] P. Gavazzo, S. Vella, C. Marchetti, M. Nizzari, R. Cancedda, and A. Pagano, "Acquisition of neuron-like electrophysiological properties in neuroblastoma cells by controlled expression of NDM29 ncRNA," Journal of Neurochemistry, vol. 119, no. 5, pp. 989-1001, 2011.

[68] S. Massone, E. Ciarlo, S. Vella et al., "NDM29, a RNA polymerase III-dependent non coding RNA, promotes amyloidogenic processing of APP and amyloid $\beta$ secretion," Biochimica et Biophysica Acta, vol. 1823, no. 7, pp. 11701177, 2012.

[69] S. Massone, I. Vassallo, G. Fiorino et al., "17A, a novel noncoding RNA, regulates GABA B alternative splicing and signaling in response to inflammatory stimuli and in Alzheimer disease," Neurobiology of Disease, vol. 41, no. 2, pp. 308-317, 2011.

[70] Q. Luo and Y. Chen, "Long noncoding RNAs and Alzheimer's disease," Journal of Clinical Interventions in Aging, vol. 11, pp. 867-872, 2016.

[71] P. Wu, X. Zuo, H. Deng, X. Liu, L. Liu, and A. Ji, "Roles of long noncoding RNAs in brain development, functional diversification and neurodegenerative diseases," Brain Research Bulletin, vol. 97, pp. 69-80, 2013.

[72] L. V. Kalia and A. E. Lang, "Parkinson's disease," Lancet, vol. 386, no. 9996, pp. 896-912, 2015.

[73] C. Carrieri, A. R. Forrest, C. Santoro et al., "Expression analysis of the long non-coding RNA antisense to Uchll (AS Uchl1) during dopaminergic cells' differentiation in vitro and in neurochemical models of Parkinson's disease," Frontiers in Cellular Neuroscience, vol. 9, p. 114, 2015.

[74] C. Scheele, N. Petrovic, M. A. Faghihi et al., "The human PINK1 locus is regulated in vivo by a non-coding natural antisense RNA during modulation of mitochondrial function," BMC Genomics, vol. 8, p. 74, 2007.

[75] J. Labbadia and R. I. Morimoto, "Huntington's disease: underlying molecular mechanisms and emerging concepts," Trends in Biochemical Sciences, vol. 38, no. 8, pp. 378-385, 2013.

[76] T. L. Young, T. Matsuda, and C. L. Cepko, "The noncoding RNA taurine upregulated gene 1 is required for differentiation of the murine retina," Current Biology, vol. 15, no. 6, pp. 501-512, 2005.

[77] A. M. Khalil, M. Guttman, M. Huarte et al., "Many human large intergenic noncoding RNAs associate with chromatinmodifying complexes and affect gene expression," Proceedings of the National Academy of Sciences, vol. 106, no. 28, pp. 11667-11672, 2009.

[78] R. Johnson, “Long non-coding RNAs in Huntington's disease neurodegeneration," Neurobiology of Disease, vol. 46, no. 2, pp. 245-254, 2012.

[79] E. B. Zhang, D. D. Yin, M. Sun et al., "P53-regulated long non-coding RNA TUG1 affects cell proliferation in human non-small cell lung cancer, partly through epigenetically regulating HOXB7 expression," Cell Death and Disease, vol. 5, article e1243, 2014.

[80] D. W. Chung, D. D. Rudnicki, L. Yu, and R. L. Margolis, “A natural antisense transcript at the Huntington's disease repeat locus regulates HTT expression," Human Molecular Genetics, vol. 20, no. 17, pp. 3767-3477, 2011.

[81] R. Medzhitov, "Origin and physiological roles of inflammation," Nature, vol. 454, no. 7203, pp. 428-435, 2008.

[82] Z. Li, T. C. Chao, K. Y. Chang et al., "The long noncoding RNA THRIL regulates TNF $\alpha$ expression through its interaction with hnRNPL," Proceedings of the National Academy of Sciences, vol. 111, no. 3, pp. 1002-1007, 2014.

[83] P. Wang, Y. Xue, Y. Han et al., "The STAT3-binding long noncoding RNA lnc-DC controls human dendritic cell differentiation," Science, vol. 344, no. 6181, pp. 310-313, 2014.

[84] H. Cui, N. Xie, Z. Tan et al., "The human long noncoding RNA lnc-IL7R regulates the inflammatory response," European Journal of Immunology, vol. 44, no. 7, pp. 20852095, 2014.

[85] M. K. Atianand, W. Hu, A. T. Satpathy et al., "A long noncoding RNA lincRNA-EPS acts as a transcriptional brake to restrain inflammation," Cell, vol. 165, no. 7, pp. 1672-1685, 2016.

[86] G. I. Bell and K. S. Polonsky, "Diabetes mellitus and genetically programmed defects in beta-cell function," Nature, vol. 414, no. 6865, pp. 788-791, 2001.

[87] C. Liu, C. P. Li, J. J. Wang, K. Shan, X. Liu, and B. Yan, "RNCR3 knockdown inhibits diabetes mellitus-induced retinal reactive gliosis," Biochemical and Biophysical Research Communications, vol. 479, no. 2, pp. 198-203, 2016. 
[88] K. Shan, C. P. Li, C. Liu, X. Liu, and B. Yan, "RNCR3: a regulator of diabetes mellitus-related retinal microvascular dysfunction," Biochemical and Biophysical Research Communications, vol. 482, no. 4, pp. 777-783, 2017.

[89] G. Z. Qiu, W. Tian, H. T. Fu, C. P. Li, and B. Liu, "Long noncoding RNA-MEG3 is involved in diabetes mellitus-related microvascular dysfunction," Biochemical and Biophysical Research Communications, vol. 471, no. 1, pp. 135-141, 2016.

[90] X. Zhu, Y. B. Wu, J. Zhou, and D. M. Kang, "Upregulation of lncRNA MEG3 promotes hepatic insulin resistance via increasing FoxO1 expression," Biochemical and Biophysical Research Communications, vol. 469, no. 2, pp. 319-325, 2016.

[91] I. Morán, I. Akerman, M. van de Bunt et al., "Human $\beta$ cell transcriptome analysis uncovers lncRNAs that are tissuespecific, dynamically regulated, and abnormally expressed in type 2 diabetes," Cell Metabolism, vol. 16, no. 4, pp. 435-448, 2012.

[92] B. F. Voight, L. J. Scott, V. Steinthorsdottir et al., "Twelve type 2 diabetes susceptibility loci identified through large-scale association analysis," Nature Genetics, vol. 42, no. 7, pp. 579-589, 2010.

[93] J. D. Amack and M. S. Mahadevan, "Myogenic defects in myotonic dystrophy," Developmental Biology, vol. 265, no. 2, pp. 294-301, 2004.

[94] R. B. Lanz, N. J. McKenna, S. A. Onate et al., “A steroid receptor coactivator, SRA, functions as an RNA and is present in an SRC-1 complex," Cell, vol. 97, no. 1, pp. 17-27, 1999.

[95] F. Hubé, G. Velasco, J. Rollin, D. Furling, and C. Francastel, "Steroid receptor RNA activator protein binds to and counteracts SRA RNA-mediated activation of MyoD and muscle differentiation," Nucleic Acids Research, vol. 39, no. 2, pp. 513-525, 2011.

[96] A. C. Mueller, M. A. Cichewicz, B. K. Dey et al., "MUNC, a long noncoding RNA that facilitates the function of MyoD in skeletal myogenesis," Molecular and Cellular Biology, vol. 35, no. 3, pp. 498-513, 2015.

[97] X. Yu, Y. Zhang, T. Li et al., "Long non-coding RNA LincRAM enhances myogenic differentiation by interacting with MyoD," Nature Communications, vol. 8, article 14016, 2017.

[98] M. Cesana, D. Cacchiarelli, I. Legnini et al., “A long noncoding RNA controls muscle differentiation by functioning as a competing endogenous RNA," Cell, vol. 147, no. 2, pp. 358-369, 2011.

[99] L. Wang, Y. Zhao, X. Bao et al., "LncRNA Dum interacts with Dnmts to regulate Dppa2 expression during myogenic differentiation and muscle regeneration," Cell Research, vol. 25, no. 3, pp. 335-350, 2015.

[100] A. J. Lusis, “Atherosclerosis," Nature, vol. 407, no. 6801, pp. 233-241, 2000.

[101] R. D. Bell, X. Long, M. Lin et al., "Identification and initial functional characterization of a human vascular cellenriched long noncoding RNA," Arteriosclerosis, Thrombosis, and Vascular Biology, vol. 34, no. 6, pp. 1249-1259, 2014.

[102] Z. Q. Zou, J. Xu, L. Li, and Y. S. Han, "Down-regulation of SENCR promotes smooth muscle cells proliferation and migration in $\mathrm{db} / \mathrm{db}$ mice through up-regulation of FoxO1 and TRPC6," Biomedicine and Pharmacotherapy, vol. 74, pp. 35-41, 2015.

[103] M. Boulberdaa, E. Scott, M. Ballantyne et al., "A role for the long noncoding RNA SENCR in commitment and function of endothelial cells," Molecular Therapy Family of Journals, vol. 24, no. 5, pp. 978-990, 2016.

[104] Y. Liu, L. Zheng, Q. Wang, and Y. W. Hu, "Emerging roles and mechanisms of long noncoding RNAs in atherosclerosis," International Journal of Cardiology, vol. 228, pp. 570-582, 2017.

[105] D. Lam, S. K. Rao, V. Ratra et al., "Cataract," Nature Reviews Disease Primer, vol. 1, article 15014, 2015.

[106] Y.Shen, L. F. Dong, R. M. Zhou et al., "Role of long non-coding RNA MIAT in proliferation, apoptosis and migration of lens epithelial cells: a clinical and in vitro study," Journal of Cellular and Molecular Medicine, vol. 20, no. 3, pp. 537-548, 2016.

[107] K. E. Lukong, K. W. Chang, E. W. Khandjian, and S. Richard, "RNA-binding proteins in human genetic disease," Trends in Genetics, vol. 24, no. 8, pp. 416-425, 2008.

[108] M. J. Moore, "From birth to death: the complex lives of eukaryotic mRNAs," Science, vol. 309, no. 5740, pp. 15141518, 2005.

[109] J. D. Keene, "RNA regulons: coordination of posttranscriptional events," Nature Review Genetics, vol. 8, no. 7, pp. 533-543, 2007.

[110] B. M. Lunde, C. Moore, and G. Varani, "RNA-binding proteins: modular design for efficient function," Nature Review Molecular and Cellular Biology, vol. 8, no. 6, pp. 479-490, 2007.

[111] U. Schmitz, X. Lai, F. Winter, O. Wolkenhauer, J. Vera, and S. K. Gupta, "Cooperative gene regulation by microRNA pairs and their identification using a computational workflow," Nucleic Acids Research, vol. 42, no. 12, pp. 7539-7552, 2014.

[112] K. J. Mavrakis, J. Van Der Meulen, A. L. Wolfe et al., “A cooperative microRNA-tumor suppressor gene network in acute T-cell lymphoblastic leukemia (T-ALL)," Nature Genetics, vol. 43, no. 7, pp. 673-678, 2011.

[113] M. N. Hinman and H. Lou, "Diverse molecular functions of $\mathrm{Hu}$ proteins," Cellular and Molecular Life Science, vol. 65, no. 20, pp. 3168-3181, 2008.

[114] K. Masuda, K. Abdelmohsen, and M. Gorospe, "RNA-binding proteins implicated in the hypoxic response," Journal of Cellular and Molecular Medicine, vol. 13, no. 9a, pp. 27592769, 2009.

[115] M. Kai, "Roles of RNA-binding proteins in DNA damage response," International Journal of Molecular Science, vol. 17, no. 3, p. 310, 2016.

[116] M. Amadio, G. Scapagnini, S. Davinelli, V. Calabrese, S. Govoni, and A. Pascale, "Involvement of ELAV RNAbinding proteins in the post-transcriptional regulation of HO-1," Frontiers in Cellular Neuroscience, vol. 8, p. 459, 2014.

[117] S. Lal, R. A. Burkhart, N. Beeharry et al., "HuR posttranscriptionally regulates WEE1: implications for the DNA damage response in pancreatic cancer cells," Cancer Research, vol. 74, no. 4, pp. 1128-1140, 2014.

[118] L. Alfano, C. Costa, A. Caporaso, D. Antonini, A. Giordano, and F. Pentimalli, "HUR protects NONO from degradation by mir320, which is induced by p53 upon UV irradiation," Oncotarget, vol. 7, no. 47, pp. 78127-78139, 2016.

[119] C. Lucchesi, M. S. Sheikh, and Y. Huang, "Negative regulation of RNA-binding protein HuR by tumor-suppressor ECRG2," Oncogene, vol. 35, no. 20, pp. 2565-2573, 2016.

[120] S. P. Han, Y. H. Tang, and R. Smith, "Functional diversity of the hnRNPs: past, present and perspectives," Biochemical Journal, vol. 430, no. 3, pp. 379-392, 2010. 
[121] H. C. Reinhardt, P. Hasskamp, I. Schmedding et al., "DNA damage activates a spatially distinct late cytoplasmic cellcycle checkpoint network controlled by MK2-mediated RNA stabilization,” Molecular Cell, vol. 40, no. 1, pp. 34-49, 2010.

[122] R. Yang, D. J. Weber, and F. Carrier, "Post-transcriptional regulation of thioredoxin by the stress inducible heterogenous ribonucleoprotein A18," Nucleic Acids Research, vol. 34, no. 4, pp. 1224-1236, 2006.

[123] E. T. Chang, P. R. Parekh, Q. Yang, D. M. Nguyen, and F. Carrier, "Heterogenous ribonucleoprotein A18 (hnRNP A18) promotes tumor growth by increasing protein translation of selected transcripts in cancer cells," Oncotarget, vol. 7, no. 9, pp. 10578-10593, 2016.

[124] A. Cammas, F. Pileur, S. Bonnal et al., "Cytoplasmic relocalization of heterogeneous nuclear ribonucleoprotein A1 controls translation initiation of specific mRNAs," Molecular Biology of the Cell, vol. 18, no. 12, pp. 5048-5059, 2007.

[125] R. W. Anantha, A. L. Alcivar, J. Ma et al., "Requirement of heterogeneous nuclear ribonucleoprotein $\mathrm{C}$ for BRCA gene expression and homologous recombination," PLoS One, vol. 8, no. 4, article e61368, 2013.

[126] A. Decorsière, A. Cayrel, S. Vagner, and S. Millevoi, "Essential role for the interaction between hnRNP H/F and a $G$ quadruplex in maintaining $\mathrm{p} 53$ pre-mRNA 3 '-end processing and function during DNA damage," Genes and Development, vol. 25, no. 3, pp. 220-225, 2011.

[127] S. Galban, Y. Kuwano, R. Pullmann Jr. et al., "RNA-binding proteins HuR and PTB promote the translation of hypoxiainducible factor 1alpha," Molecular and Cellular Biology, vol. 28, no. 1, pp. 93-107, 2008.

[128] A. S. Mastrocola, S. H. Kim, A. T. Trinh, L. A. Rodenkirch, and R. S. Tibbetts, "The RNA-binding protein fused in sarcoma (FUS) functions downstream of poly(ADP-ribose) polymerase (PARP) in response to DNA damage," Journal of Biological Chemistry, vol. 288, no. 34, pp. 24731-24741, 2013.

[129] W. Y. Wang, L. Pan, S. C. Su et al., "Interaction of FUS and HDAC1 regulates DNA damage response and repair in neurons," Nature Neuroscience, vol. 16, no. 10, pp. 13831391, 2013.

[130] P. Anderson and N. Kedersha, "Stress granules: the Tao of RNA triage," Trends in Biochemical Sciences, vol. 33, no. 3, pp. 141-150, 2008.

[131] K. Arimoto-Matsuzaki, H. Saito, and M. Takekawa, “TIA1 oxidation inhibits stress granule assembly and sensitizes cells to stress-induced apoptosis," Nature Communications, vol. 7, article 10252, 2016.

[132] K. Jin, W. Li, T. Nagayama et al., "Expression of the RNAbinding protein TIAR is increased in neurons after ischemic cerebral injury," Journal of Neuroscience Research, vol. 59, no. 6, pp. 767-774, 2000.

[133] H. S. Kim, Y. Kuwano, M. Zhan et al., "Elucidation of a C-rich signature motif in target mRNAs of RNA-binding protein TIAR," Molecular and Cellular Biology, vol. 27, no. 19, pp. 6806-6817, 2007.

[134] F. Hellborg, W. Qian, C. Mendez-Vidal et al., "Human wig-1, a p53 target gene that encodes a growth inhibitory zinc finger protein," Oncogene, vol. 20, no. 39, pp. 5466-5474, 2001.

[135] A. Vilborg, J. A. Glahder, M. T. Wilhelm et al., “The p53 target Wig-1 regulates p53 mRNA stability through an AU-rich element," Proceedings of the National Academy of Sciences of the United States of America, vol. 106, no. 37, pp. 1575615761, 2009.

[136] C. Bersani, L. D. Xu, A. Vilborg, W. O. Lui, and K. G. Wiman, "Wig-1 regulates cell cycle arrest and cell death through the p53 targets FAS and 14-3-3sigma," Oncogene, vol. 33, no. 35, pp. 4407-4417, 2014.

[137] K. Masuda, Y. Kuwano, K. Nishida, and K. Rokutan, “General RBP expression in human tissues as a function of age," Ageing Research Reviews, vol. 11, no. 4, pp. 423-431, 2012.

[138] G. Toba, D. Yamamoto, and K. White, "Life-span phenotypes of elav and Rbp9 in Drosophila suggest functional cooperation of the two ELAV-family protein genes," Archives of Insect Biochemistry and Physiology, vol. 74, no. 4, pp. 261265, 2010.

[139] M. Hashimoto, T. Tsugawa, H. Kawagishi, A. Asai, and M. Sugimoto, "Loss of HuR leads to senescence-like cytokine induction in rodent fibroblasts by activating NF-kappaB," Biochimica et Biophysica Acta, vol. 1840, no. 10, pp. 30793087, 2014.

[140] K. Masuda, B. Marasa, J. L. Martindale, M. K. Halushka, and M. Gorospe, "Tissue- and age-dependent expression of RNAbinding proteins that influence mRNA turnover and translation," Aging (Albany NY), vol. 1, no. 8, pp. 681-698, 2009.

[141] L. Pang, H. Tian, N. Chang et al., "Loss of CARM1 is linked to reduced HuR function in replicative senescence," $B M C$ Molecular Biology, vol. 14, p. 15, 2013.

[142] N. Chang, J. Yi, G. Guo et al., "HuR uses AUF1 as a cofactor to promote p16INK4 mRNA decay," Molecular and Cellular Biology, vol. 30, no. 15, pp. 3875-3886, 2010.

[143] G. E. Guo, L. W. Ma, B. Jiang, J. Yi, T. J. Tong, and W. G. Wang, "Hydrogen peroxide induces p16(INK4a) through an AUF1-dependent manner," Journal of Cellular Biochemistry, vol. 109, no. 5, pp. 1000-1005, 2010.

[144] A. R. Pont, N. Sadri, S. J. Hsiao, S. Smith, and R. J. Schneider, "mRNA decay factor AUF1 maintains normal aging, telomere maintenance, and suppression of senescence by activation of telomerase transcription," Molecular Cell, vol. 47, no. 1, pp. 5-15, 2012.

[145] S. Waris, M. C. Wilce, and J. A. Wilce, "RNA recognition and stress granule formation by TIA proteins," International Journal of Molecular Science, vol. 15, no. 12, pp. 2337723388, 2014.

[146] C. Sanchez-Jimenez and J. M. Izquierdo, "T-cell intracellular antigen (TIA)-proteins deficiency in murine embryonic fibroblasts alters cell cycle progression and induces autophagy," PLoS One, vol. 8, no. 9, article e75127, 2013.

[147] I. A. Vlasova, N. M. Tahoe, D. Fan et al., "Conserved GU-rich elements mediate mRNA decay by binding to CUG-binding protein 1," Molecular Cell, vol. 29, no. 2, pp. 263-270, 2008.

[148] P. Iakova, G. L. Wang, L. Timchenko et al., "Competition of CUGBP1 and calreticulin for the regulation of p21 translation determines cell fate," The EMBO Journal, vol. 23, no. 2, pp. 406-417, 2004.

[149] N. A. Timchenko, G. L. Wang, and L. T. Timchenko, "RNA CUG-binding protein 1 increases translation of $20-\mathrm{kDa}$ isoform of CCAAT/enhancer-binding protein beta by interacting with the alpha and beta subunits of eukaryotic initiation translation factor 2," Journal of Biological Chemistry, vol. 280, no. 21, pp. 20549-20557, 2005. 
[150] L. T. Timchenko, E. Salisbury, G. L. Wang et al., "Age-specific CUGBP1-eIF2 complex increases translation of CCAAT/ enhancer-binding protein beta in old liver," Journal of Biological Chemistry, vol. 281, no. 43, pp. 32806-32819, 2006.

[151] J. Jin, G. L. Wang, E. Salisbury, L. Timchenko, and N. A. Timchenko, "GSK3beta-cyclin D3-CUGBP1-eIF2 pathway in aging and in myotonic dystrophy," Cell Cycle, vol. 8, no. 15, pp. 2356-2359, 2009.

[152] C. R. Ross, S. E. Brennan-Laun, and G. M. Wilson, "Tristetraprolin: roles in cancer and senescence," Ageing Research Reviews, vol. 11, no. 4, pp. 473-484, 2012.

[153] D. Frasca, A. M. Landin, R. L. Riley, and B. B. Blomberg, "Mechanisms for decreased function of B cells in aged mice and humans," Journal of Immunology, vol. 180, no. 5, pp. 2741-2746, 2008.

[154] S. Sanduja, V. Kaza, and D. A. Dixon, "The mRNA decay factor tristetraprolin (TTP) induces senescence in human papillomavirus-transformed cervical cancer cells by targeting E6-AP ubiquitin ligase," Aging (Albany NY), vol. 1, no. 9, pp. 803-817, 2009.

[155] B. C. Kim, H. C. Lee, J. J. Lee et al., "Wig1 prevents cellular senescence by regulating p21 mRNA decay through control of RISC recruitment," The EMBO Journal, vol. 31, no. 22, pp. 4289-4303, 2012.

[156] R. B. Darnell, "RNA protein interaction in neurons," Annual Review Neuroscience, vol. 36, pp. 243-270, 2013.

[157] S. C. Lenzken, T. Achsel, M. T. Carrì, and S. M. L. Barabino, "Neuronal RNA -binding proteins in health and disease," Wiley Interdisciplinary Reviews: RNA, vol. 5, pp. 565-576, 2014.

[158] C. E. Holt and S. L. Bullock, "Subcellular mRNA localization in animal cells and why it matters," Science, vol. 326, no. 5957, pp. 1212-1216, 2009.

[159] J. Sreedharan, I. P. Blair, V. B. Tripathi et al., "TDP-43 mutations in familial and sporadic amyotrophic lateral sclerosis," Science, vol. 319, no. 5870, pp. 1668-1672, 2008.

[160] S. C. Ling, M. Polymenidou, and D. W. Cleveland, "Converging mechanisms in ALS and FTD: disrupted RNA and protein homeostasis," Neuron, vol. 79, no. 3, pp. 416-438, 2013.

[161] O. A. Sofola, P. Jin, Y. Qin et al., "RNA-binding proteins hnRNP A2/B1 and CUGBP1 suppress fragile X CGG premutation repeat-induced neurodegeneration in a Drosophila model of FXTAS," Neuron, vol. 55, no. 4, pp. 565-571, 2007.

[162] H. J. Kim, N. C. Kim, Y. D. Wang et al., "Mutations in prion-like domains in hnRNPA2B1 and hnRNPA1 cause multisystem proteinopathy and ALS," Nature, vol. 495, no. 7442, pp. 467-473, 2013.

[163] E. B. Lee, V. M. Lee, and J. Q. Trojanowski, "Gains or losses: molecular mechanisms of TDP43-mediated neurodegeneration," Nature Reviews Neuroscience, vol. 13, no. 1, pp. 3850, 2011.

[164] C. Vance, B. Rogelj, T. Hortobagyi et al., "Mutations in FUS, an RNA processing protein, cause familial amyotrophic lateral sclerosis type 6," Science, vol. 323, no. 5918, pp. 1208-1211, 2009.

[165] T. J. Kwiatkowski Jr., D. A. Bosco, A. L. Leclerc et al., "Mutations in the FUS/TLS gene on chromosome 16 cause familial amyotrophic lateral sclerosis," Science, vol. 323, no. 5918, pp. 1205-1208, 2009.

[166] N. Perrone-Bizzozero and C. W. Bird, "Role of HuD in nervous system function and pathology," Frontiers in Bioscience (Schol Ed), vol. 5, pp. 554-563, 2013.
[167] S. Hayashi, M. Yano, M. Igarashi, H. J. Okano, and H. Okano, "Alternative role of $\mathrm{HuD}$ splicing variants in neuronal differentiation," Journal of Neuroscience Research, vol. 93, no. 3, pp. 399-409, 2015.

[168] M. J. Kang, K. Abdelmohsen, E. R. Hutchison et al., "HuD regulates coding and noncoding RNA to induce $\mathrm{APP} \rightarrow \mathrm{A} \beta$ processing," Cell Reports, vol. 7, no. 5, pp. 1401-1409, 2014.

[169] J. D. Richter, G. J. Bassell, and E. Klann, "Dysregulation and restoration of translational homeostasis in fragile $\mathrm{X}$ syndrome," Nature Reviews Neuroscience, vol. 16, no. 10, pp. 595-605, 2015.

[170] Z. Li, Y. Zhang, L. Ku, K. D. Wilkinson, S. T. Warren, and Y. Feng, "The fragile $\mathrm{X}$ mental retardation protein inhibits translation via interacting with mRNA," Nucleic Acids Research, vol. 29, no. 11, pp. 2276-2283, 2001.

[171] E. K. Lee, H. H. Kim, Y. Kuwano et al., "hnRNP C promotes APP translation by competing with FMRP for APP mRNA recruitment to P bodies," Nature Structure and Molecular Biology, vol. 17, no. 6, pp. 732-739, 2010.

[172] A. Borreca, K. Gironi, G. Amadoro, and M. AmmassariTeule, "Opposite dysregulation of fragile-X mental retardation protein and heteronuclear ribonucleoprotein $\mathrm{C}$ protein associates with enhanced APP translation in Alzheimer disease," Molecular Neurobiology, vol. 53, no. 5, pp. 32273234, 2016.

[173] F. He, A. Krans, B. D. Freibaum, J. P. Taylor, and P. K. Todd, "TDP-43 suppresses CGG repeat-induced neurotoxicity through interactions with HnRNP A2/B1," Human Molecular Genetics, vol. 23, no. 19, pp. 5036-5051, 2014.

[174] X. Y. Liu, H. L. Li, J. B. Su et al., "Regulation of RAGE splicing by hnRNP A1 and Tra2beta-1 and its potential role in AD pathogenesis," Journal of Neurochemistry, vol. 133, no. 2, pp. 187-198, 2015.

[175] A. Berson, S. Barbash, G. Shaltiel et al., "Cholinergic-associated loss of hnRNP-A/B in Alzheimer's disease impairs cortical splicing and cognitive function in mice," $E M B O$ Molecular Medicine, vol. 4, no. 8, pp. 730-742, 2012.

[176] F. J. Martinez, G. A. Pratt, E. L. Van Nostrand et al., "ProteinRNA networks regulated by normal and ALS-associated mutant HNRNPA2B1 in the nervous system," Neuron, vol. 92, no. 4, pp. 780-795, 2016.

[177] K. Mizukami, M. Ishikawa, M. Iwakiri et al., "Immunohistochemical study of the hnRNP A2 and B1 in the hippocampal formations of brains with Alzheimer's disease," Neuroscience Letters, vol. 386, no. 2, pp. 111-115, 2005.

[178] G. S. Hotamisligil, "Inflammation and metabolic disorders," Nature, vol. 444, pp. 860-867, 2006.

[179] P. W. Wilson, R. B. D'Agostino, H. Parise, L. Sullivan, and J. B. Meigs, "Metabolic syndrome as a precursor of cardiovascular disease and type 2 diabetes mellitus," Circulation, vol. 112, no. 20, pp. 3066-3072, 2005.

[180] W. Kim and E. K. Lee, "Post-transcriptional regulation in metabolic diseases," RNA Biology, vol. 9, no. 6, pp. 1-9, 2012.

[181] E. K. Lee, W. Kim, K. Tominaga et al., "RNA-binding protein $\mathrm{HuD}$ controls insulin translation," Molecular Cell, vol. 45, no. 6, pp. 826-835, 2012.

[182] C. Kim, H. Lee, H. Kang et al., "RNA-binding protein $\mathrm{HuD}$ reduces triglyceride production in pancreatic beta cells by enhancing the expression of insulin-induced gene 1," Biochimica et Biophysica Acta, vol. 1859, no. 4, pp. 675-685, 2016. 
[183] C. Kim, W. Kim, H. Lee et al., "The RNA-binding protein $\mathrm{HuD}$ regulates autophagosome formation in pancreatic beta cells by promoting autophagy-related gene 5 expression," Journal of Biological Chemistry, vol. 289, no. 1, pp. 112-121, 2014.

[184] J. A. Juan-Mateu, T. H. Rech, O. Villate et al., "Neuronenriched RNA-binding proteins regulate pancreatic beta cell function and survival," Journal of Biological Chemistry, vol. 292, no. 8, pp. 3466-3480, 2017.

[185] S. Sen, I. Talukdar, and N. J. Webster, "SRp20 and CUG-BP1 modulate insulin receptor exon 11 alternative splicing," Molecular and Cellular Biology, vol. 29, no. 3, pp. 871-880, 2009.

[186] K. Zhai, L. Gu, Z. Yang et al., "RNA-binding protein CUGBP1 regulates insulin secretion via activation of phosphodiesterase 3B in mice," Diabetologia, vol. 59, no. 9, pp. 1959-1967, 2016.

[187] S. K. Verma, V. Deshmukh, P. Liu et al., "Reactivation of fetal splicing programs in diabetic hearts is mediated by protein kinase C signaling," Journal of Biological Chemistry, vol. 288, no. 49, pp. 35372-35386, 2013.

[188] G. W. Yeo, N. G. Coufal, T. Y. Liang, G. E. Peng, X. D. Fu, and F. H. Gage, "An RNA code for the FOX2 splicing regulator revealed by mapping RNA-protein interactions in stem cells," Nature Structure and Molecular Biology, vol. 16, no. 2, pp. 130-137, 2009.

[189] C. A. Nutter, E. A. Jaworski, S. K. Verma et al., "Dysregulation of RBFOX2 is an early event in cardiac pathogenesis of diabetes," Cell Reports, vol. 15, no. 10, pp. 2200-2213, 2016.

[190] N. Dai, J. Rapley, M. Angel, M. F. Yanik, M. D. Blower, and J. Avruch, "mTOR phosphorylates IMP2 to promote IGF2 mRNA translation by internal ribosomal entry," Genes and Development, vol. 25, no. 11, pp. 1159-1172, 2011.

[191] R. Saxena, B. F. Voight, V. Lyssenko et al., "Genome-wide association analysis identifies loci for type 2 diabetes and triglyceride levels," Science, vol. 316, no. 5829, pp. 13311336, 2007.

[192] L. J. Scott, K. L. Mohlke, L. L. Bonnycastle et al., "A genomewide association study of type 2 diabetes in Finns detects multiple susceptibility variants," Science, vol. 316, no. 5829, pp. 1341-1345, 2007.

[193] N. Dai, L. Zhao, D. Wrighting et al., "IGF2BP2/IMP2deficient mice resist obesity through enhanced translation of Ucp1 mRNA and other mRNAs encoding mitochondrial proteins," Cell Metabolism, vol. 21, no. 4, pp. 609-621, 2015.

[194] A. Martinez-Sanchez, G. A. Rutter, and M. Latreille, "MiRNAs in beta-cell development, identity, and disease," Frontiers in Genetics, vol. 7, p. 226, 2016.

[195] F. Olivieri, M. C. Albertini, M. Orciani et al., "DNA damage response (DDR) and senescence: shuttled inflammamiRNAs on the stage of inflamm-aging," Oncotarget, vol. 6, no. 34, pp. 35509-35521, 2015.

[196] Y. Zhang, B. Yu, J. He, and D. Chen, "From nutrient to MicroRNA: a novel insight into cell signaling involved in skeletal muscle development and disease," International Journal of Biological Sciences, vol. 12, no. 10, pp. 12471261, 2016.

[197] A. Castello, B. Fischer, K. Eichelbaum et al., "Insights into RNA biology from an atlas of mammalian mRNA-binding proteins," Cell, vol. 149, no. 6, pp. 1393-1406, 2012.
[198] Y. Neelamraju, S. Hashemikhabir, and S. C. Janga, "The human RBPome: from genes and proteins to human disease," Journal of Proteomics, vol. 127, Part A, pp. 61-70, 2015.

[199] J. H. Li, S. Liu, L. L. Zheng et al., "Discovery of proteinlncRNA interactions by integrating large-scale CLIP-Seq and RNA-Seq datasets," Frontiers in Bioengineering and Biotechnology, vol. 2, p. 88, 2014. 


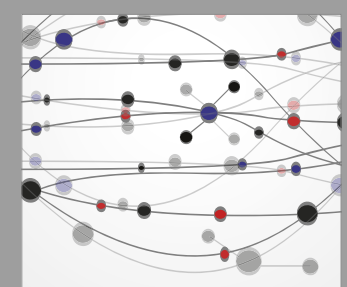

The Scientific World Journal
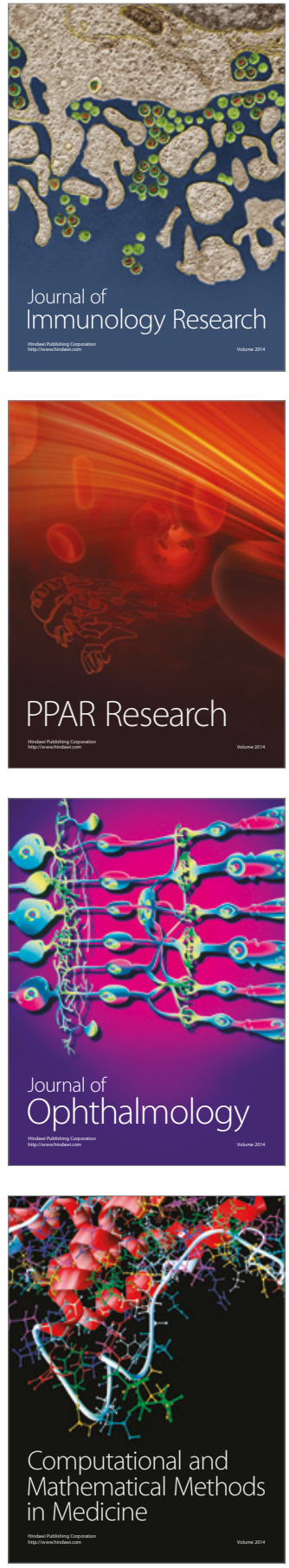

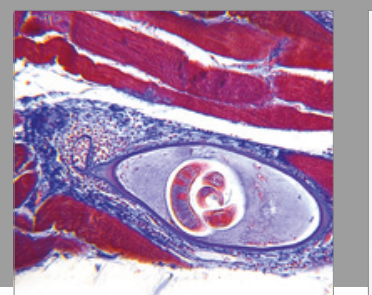

Gastroenterology Research and Practice
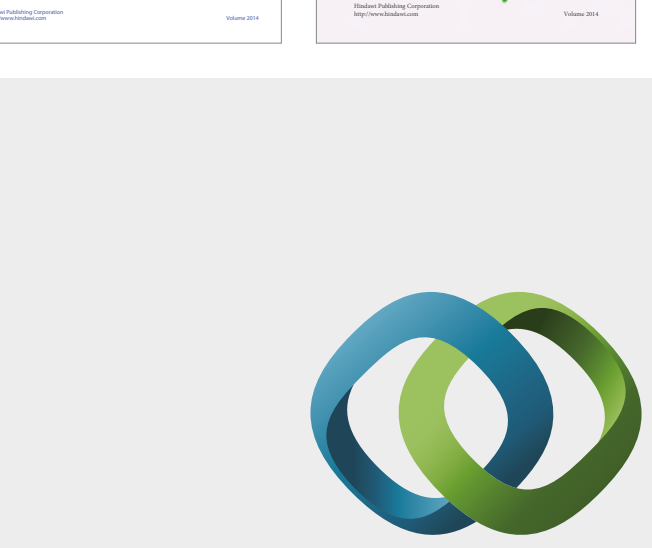

\section{Hindawi}

Submit your manuscripts at

https://www.hindawi.com
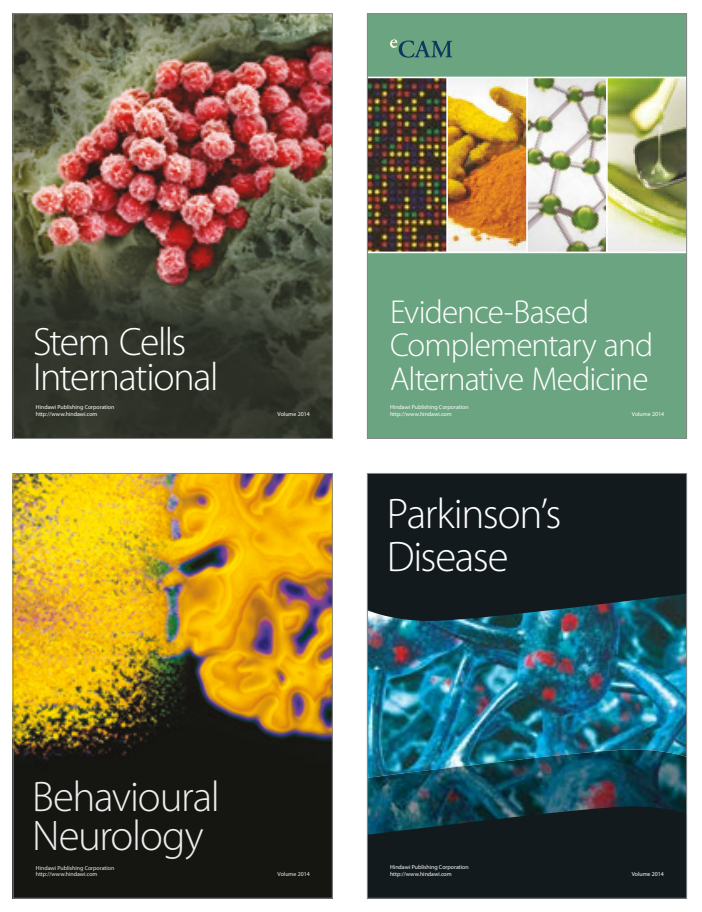
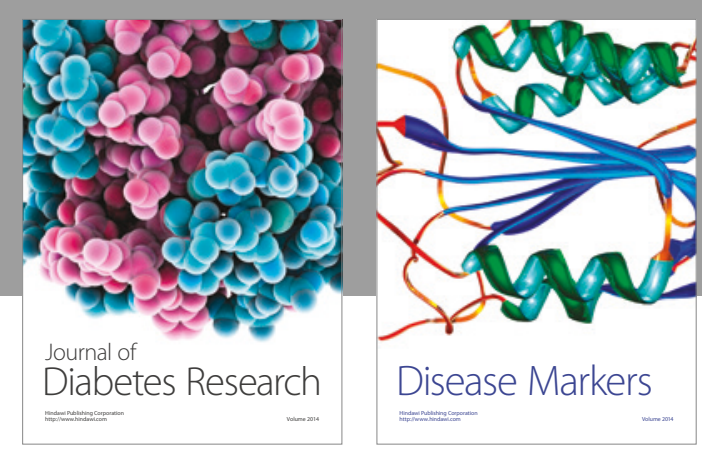

Disease Markers
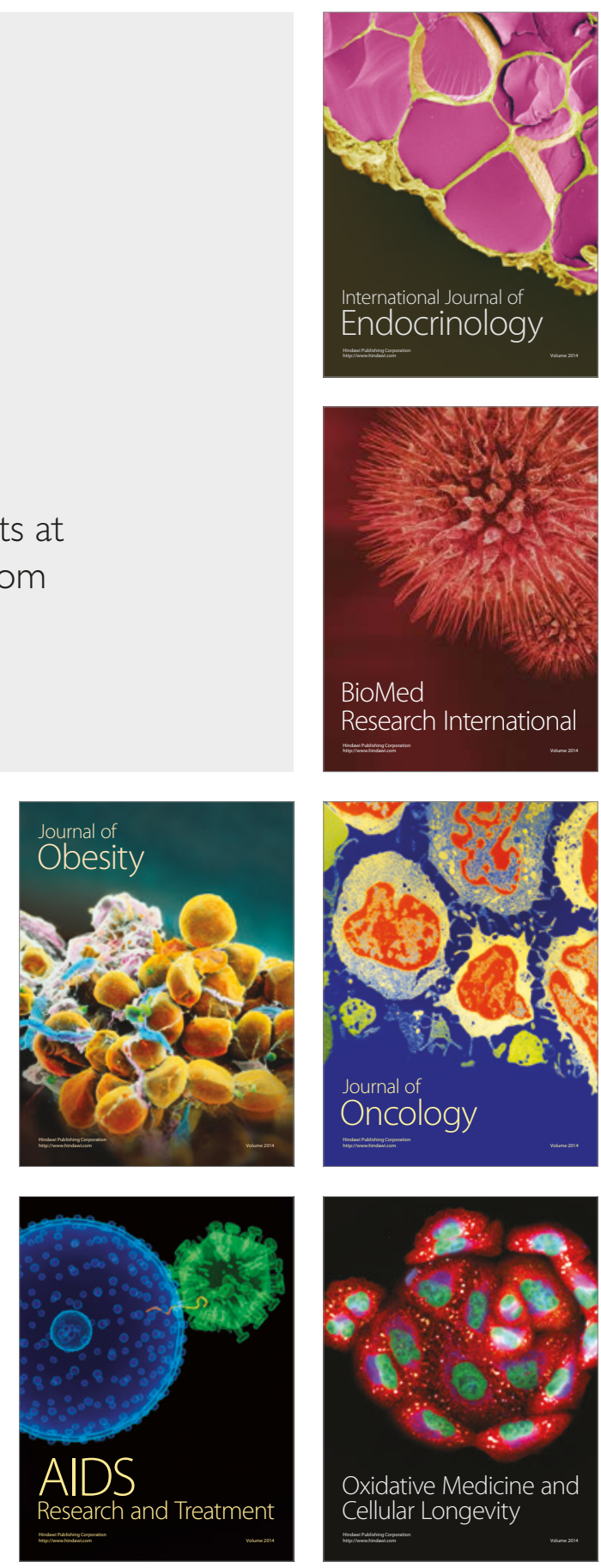